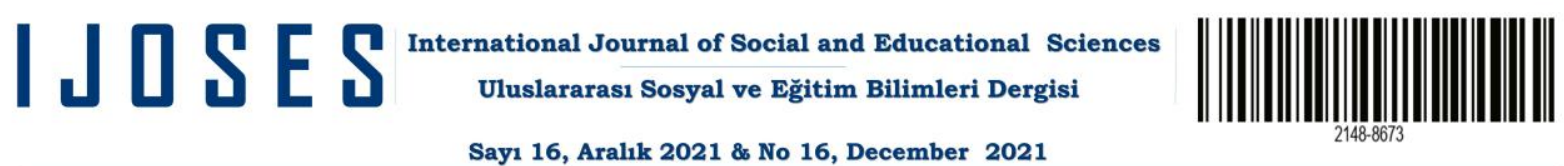

\section{Asimetrik Garch Modellerle Riske Maruz Değer (RMD) Analizi: Altın, Bist 100 Endeksi ve Dolar'dan Oluşan Portföy Üzerinde Bir Uygulama}

Value at Risk (Var) Analysis with The Asymmetric Garch Models: An Application on The Portfolio Consisting of Gold, Bist 100 Index and Dollar

\section{Muhammet Sait Işıldak}

Dr. Öğretim Üyesi

Tokat Gazi Osman Paşa Üniversitesi muhammetsait.isildak@gop.edu.tr ORCID ID: 0000-0001-5715-7090

\section{Makale Bilgisi / Article Information}

Makale Türü / Article Type : Araştırma Makalesi

Geliş Tarihi/Received : 2 Ağustos 2021

Kabul Tarihi / Accepted : 8 Eylül 2021

Yayın Tarihi / Published : 15 Aralık 2021

DOI Number : :10.20860/ijoses.977206

\section{Kaynak Gösterme / Citation}

Işıldak, M. S. “Asimetrik Garch Modellerle Riske Maruz Değer (RMD) Analizi: Altın, Bist 100 Endeksi ve Dolar'dan Oluşan Portföy Üzerinde Bir Uygulama". Uluslararası Sosyal ve Eğitim Bilimleri Dergisi, 16 (2021): 41-67. 


\title{
Asimetrik Garch Modellerle Riske Maruz Değer (RMD) Analizi: Altın, Bist 100 Endeksi ve Dolar'dan Oluşan Portföy Üzerinde Bir Uygulama
}

\author{
Value at Risk (Var) Analysis with The Asymmetric Garch Models: An Application on The Portfolio \\ Consisting of Gold, Bist 100 Index and Dollar
}

\section{Muhammet Sait Ișıldak}

$\ddot{O} z$

Finansal varlıkların risklerinin zamanla değiştiği bilinmektedir. Riskler, iyi haber veya kötü haberlere bağı olarak daha fazla artmakta veya azalmaktadır. Riski azaltmanın bir yolu da bir portföy oluşturmaktır. Bu çalışmada, riski azaltıp azaltmadığını ölçmek için Altın, Bist 100 endeksi ve Dolar'dan oluşan bir portföy oluşturulmuştur. Bu portföy üzerinde asimetrik GARCH modeller kullanarak Altın, Bist 100 endeksi ve Dolar serileri üzerinde koşullu RMD değerler ile portföy RMD değerleri karşılaştııılarak riske ölçümü yapılması amaçlanmıştır. RMD ve volatiliteyi birlikte ele alan birçok çalışma vardır. Ancak, volatilite analizinde uygun model seçiminin yapılması ve sağlanan volatilite değerleriyle RMD analizi yapılması bu çalışmayı diğerlerinden ayıran özelliktir. Yapılan istatistik analizler sonucunda, serilerin normal dağılmaması ve değişen varyansa sahip olması nedeniyle genelleştirilmiş otoregresif koşullu değişen varyans (GARCH) yöntemlerine başvurulmuştur. ARMA süreci çalıştırlarak uygun $\mathrm{GARCH}$ yöntemi bulunmuştur. Bulunan uygun $\operatorname{GARCH}(1,1)$ modele göre volatilite değerleri ile \%95 ve \%99 güven düzeylerinde 1, 10 ve 252 gün için RMD analizi yapıımıştır. Çalışmanın sonucu olarak, Altın, Bist 100 endeksi ve Dolar serilerinde güven düzeyi düştükçe riskin artıı̆ı bulgusuna ulaşılmışır. Gün sayısı arttıkça risk daha fazla artış göstermektedir. Ayrıca, tek tek RMD değerleri ile RMD portföy değerleri karşılaştııılmıştır. RMD portföy değerlerinin RMD değerlerinden daha düşük çıkmıştır. Dolayısıyla, serilerde portföy etkisi olduğu açıkça görülmüştür.

Anahtar kelimeler: GARCH, RMD, volatilite, portföy, zaman serisi modelleri.

\section{Abstract}

It is known that the risks of financial assets change over time. Risks more increase or decrease depending on the good news or bad news. One way to reduce risk is to create a portfolio. In this study, a portfolio consisting of Bist 100 index and Dollar was created to measure whether it reduces risk. By using asymmetric GARCH models on this portfolio, it is aimed to measure risk by comparing conditional VaR values on Gold, Bist 100 index and Dollar series with portfolio VaR values. There are many studies that deal with $\mathrm{VaR}$ and volatility together. However, choosing the appropriate model in volatility analysis and performing VaR analysis with the provided volatility values are the features that distinguish this study from others. As a result of the statistical analysis, generalized autoregressive conditional variable variance (GARCH) methods were used because the series were not normally distributed and had varying variance. The appropriate GARCH method was found by running the ARMA process. VaR (Value at Risk) analysis was performed for 1, 10 and 252 days at $95 \%$ and $99 \%$ confidence levels with volatility values according to the appropriate GARCH $(1,1)$ model found. As a result of the study, it was found that the risk increased as the confidence level decreased in Gold, BIST 100 index and Dollar series. The risk increases as the number of days increases. In addition, on one VaR compared values and VaR portfolio values. VaR portfolio values are lower than $\mathrm{VaR}$ values. Therefore, it is clearly seen that there is a portfolio effect in the series.

Keywords: GARCH, value at risk, volatility, portfolio, time series models. 


\section{Extended Summary}

\section{Purpose and Significance:}

It is known that the risks of financial assets change over time. Depending on good news or bad news risks increase or decrease more. One way to reduce risk is to build a portfolio. In this study, a portfolio consisting of Gold, Bist 100 index and Dollar was created to measure whether it reduced risk.

It is aimed to measure risk by comparing conditional $\mathrm{VaR}$ values and portfolio $\mathrm{VaR}$ values by using asymmetric GARCH models on a portfolio consisting of Gold, Bist 100 index and Dollar. However, choosing the appropriate model in volatility analysis and performing VaR analysis with the provided volatility values are the features that distinguish this study from others.

\section{Methodology:}

The scope of the study is a hypothetic portfolio with an equal share of gold (TL/Kg), Bist 100 index and USD. The aim of the study is to measure risk on a portfolio with RMD analysis. Using asymmetric GARCH models, conditional RMD values and RMD portfolio values were compared on gold, Bist 100 index and Dollar series. Data for assets in the portfolio between 05/01/2010-10/06/2021 were used. The Bist 100 index and the closing data for 2875 working days of the Dollar were obtained from the Electronic Data Distribution System of the Central Bank of the Republic of Turkey. The closing data for 2875 working days of gold were obtained from Borsa İstanbul database. Eviews12 and Excel software were used in the calculations.

In order to be worked with financial time series, the necessary statistical analyses must be made. The data used in parametric methods should be independent, normally distributed, with constant variance and equally spaced. The correct results of parametric tests depend on the stable series. For stationarity testing, is usually used unit root testing. Goldfeld-Quandt test, Park test, Glejser test, Breusch-Pagan test, White test and Similarity Ratio test are usually used to determine whether there is heteroskedasticity. Tests such as graphic method, Durbin-Watson d-statistics, Breusch-Godfrey LM test can usually be performed to determine whether the data is autocorrelation.

$\mathrm{VaR}$ calculations are an analysis made under the assumption that the returns on financial assets are normally distributed. Jarque-Bera test and Kolmogorov-Smirnov tests are generally used together to measure normality. If the financial data do not show a normal distribution, conditional VaR is used instead of VaR. Conditional VaR measures the expected loss (Expected Shortfall) due to non-normal distribution of data. The expected loss is the average of losses exceeding VaR and is higher than normal $\mathrm{VaR}$. Conditional VaR is the average of 5\% expected losses at a 95\% confidence level. Contingent VaR is also known as average value-at-risk, tail value-at-risk, and expected loss. Contingent VaR is considered a more consistent measure of risk than VaR. In financial asset risk measurement, volatility is used as a criterion. Volatility is a statistical measure of price changes of a financial asset. Many GARCH models are used to measure the volatility of financial assets that do not have normal distribution. The most commonly used GARCH models are Threshold GARCH, Exponential GARCH and Asymmetric Power ARCH models.

Volatility calculated according to GARCH models can be used in RMD calculation. Thus, the lowest return or maximum loss to be endured on the financial asset can be calculated by RMD. Therefore, statistical analyses it is necessary to do were made for gold, Bist 100 index and dollar series. As a result of the analyses, it was decided to perform conditional RMD analysis. The risk exposure values as a result of the VaR analysis of the Gold, Bist 100 and Dollar series are as follows.

The portfolio of gold, Bist 100 and Dollar series has a confidence level of $\mathrm{Z}=0.95$ and the maximum probability of losses for $\mathrm{T}=1$ day is $0.04 \%$. 
The portfolio of gold, Bist 100 and Dollar series has a confidence level of $\mathrm{Z}=0.95$ and the maximum probability of loss for $\mathrm{T}=10$ days is $0.12 \%$.

The portfolio of gold, Bist 100 and Dollar series has a confidence level of $Z=0.95$ and the maximum probability of loss for $\mathrm{T}=252$ days is $0.63 \%$.

The portfolio of gold, Bist 100 and Dollar series has a confidence level of $\mathrm{Z}=0.99$ and the maximum probability of losses for $\mathrm{T}=1$ day is $0.06 \%$.

The portfolio of gold, Bist 100 and Dollar series has a confidence level of $Z=0.99$ and the maximum probability of losses for $\mathrm{T}=10$ days is $0.18 \%$.

The portfolio of gold, Bist 100 and Dollar series has a confidence level of $\mathrm{Z}=0.99$ and the maximum probability of loss for $\mathrm{T}=252$ days is $0.89 \%$.

First, necessary analyzes were made to use the GARCH model, and ARMA (3.1) for Gold and Dollar and ARMA (1.1) for Bist 100 were determined as the appropriate model. For these ARMA models was tested whether or not ARCH effect. It was found appropriate to perform GARCH analysis for these series, which were determined to have ARCH effect.

Secondly, GARCH, TARCH, EGARCH and PARCH models were compared according to the criteria used in GARCH model selection. TARCH model was chosen for gold and dollar. It has been determined that the PARCH model is the appropriate model for the Bist 100 index. According to the established TARCH and PARCH models, it was analyzed whether the ARCH effect was eliminated or not.

Third, VaR analysis was performed with the volatility values found for these series, which were found to have no ARCH effect. By creating an equally weighted portfolio for 1, 10, 252 days for each series separately $95 \%$ and $99 \%$ confidence levels value-at-risk analysis was performed.

As a result, as the confidence level drops in the Gold, Bist 100 and Dollar series, the higher the risk. The risk increases as the more of days increases. It is clearly seen that there is a portfolio effect in the portfolio consisting of Gold, Bist 100 and Dollar series. For other studies, analyzes with portfolios consisting of different series, time intervals or weights can be suggested.

\section{Giriş}

Finansal piyasaların en önemli konusu risk ve getiridir (Sotic ve Rajic, 2015:18). Risk gelecekte öngörülemeyen belirsizliklerdir (Treasury, 2004:9). Risk beklenmeyen (getiriler, öz kaynak veya aktiflerin net değerinde oluşan) sonuçların volatilitesidir (Jorion, 2007:3). Risk, istenmeyen bir sonucun olma olasılığıdır (Baas, Ramamasy, Dey de Pryck, ve Battista, 2008:6). Olası alternatiflerin bilindiğini varsayarak, gelecekteki alternatiflerinin öngörülmesidir. Belirsizlik ise, gelecekteki olası alternatiflerin ve bunların gerçekleşme olasılıklarının bilinmediği bir durumdur (Bitaraf ve Shahriari, 2012:66) Risk ve belirsizlik hem nicel hem de nitel olarak ölçülebilir ancak risk için bir oluşma olasılığı atanarak anlaşılabilirken, belirsizlik için daha fazla olasılığı içeren bulanık metodoloji kullanılarak anlaşılabilir (Toma, Chiriţă ve Şarpe 2012:979). Risk, yönetilebilir ve en aza indirilebilir ancak belirsizlik, yatırımcının kontrolü dışındadır (Echaust, 2019:35).

Risk ölçümünde nominal değer yaklaşımı, standart sapma, duyarlılık katsayıları ve riske maruz değer gibi çeşitli yöntemler kullanılmaktadır (Altay 2015:20). RMD, belirli bir güven düzeyi ve sürede yatırımda oluşacak değer kaybını gösteren bir risk ölçüsüdür (Altay 2015:75). RMD, belirli bir sürede belirlenmiş bir güven aralığında oluşabilecek en yüksek zararı ifade eden istatistiksel bir yöntemdir (Altıntaş, 2006:21). RMD, Varyans-Kovaryans yöntemi, tarihi simülasyon yöntemi ve Monte Carlo Simülasyonu yöntemiyle hesaplanabilmektedir. Geçmiş verileri kullanan RMD yöntemlerinin 
temelinde geçmiş geleceğin bir göstergesi olduğu varsayımı vardır (Altay, 2015:3). Varyans-kovaryans yöntemi parametrik yöntemdir. RMD hesaplamasında en az bir yıllık veri kullanılması Basel Komitesi tarafindan tavsiye edilmektedir (Altıntaş, 2006:22).

Risk ölçülebilir olmalıdır. Sayısal olmayan risk ölçülemez. Dolayısıyla riski sayısal değerler olarak ölçmek onu yönetebilmek için gereklidir. RMD yöntemi riski sayısallaştırdığg ve varlık üzerindeki değer kaybını ölçtüğü için kabul görmüştür. Bu yöntemin de eksik tarafları vardır. Yöntemin eksiklikleri stres testleri ile desteklenmeye çalışılmıştır. Bu bağlamda, Basel $2.5^{\prime}$ da strese tabi riske maruz değer hesaplanmas1 ve bunun riske maruz değere eklenmesi istenmektedir (Cangürel vd., 2012:15).

Çalışmada, Altın, Bist 100 ve Dolar serilerinden oluşan portföyün riske maruz değer hesaplaması, genelleştirilmiş otoregresif koşullu değişen varyans $(\mathrm{GARCH})$ modellerin analizi yapılmıştır. GARCH modeller ile genelde volatilite hesaplaması yapılmaktadır. RMD analizinde de volatilite kullanılmaktadır. Finansal zaman serileri normal dağılım göstermediklerinden dolayı volatilitenin hesaplanması daha uygun olacaktır. İlk önce volatilite hesaplaması yapıp daha sonra RMD analizi yapmak daha doğru olacaktır. Dolayısıyla, çalışmada kullanılan zaman serilerinin volatilitesi bulunmuş, daha sonra parametrik yöntem olan varyans-kovaryans yöntemi kullanılarak RMD hesaplamaları yapılmıştır. Literatürde RMD ve volatilite hesaplamaları çoğunlukla ayrı ayrı ele alınmaktadır. RMD ve volatilitenin birlikte ele alan birçok çalışma vardır. Ancak, volatilite analizinde uygun model seçiminin yapılması ve sağlanan volatilite değerleriyle RMD analizi yapılması bu çalışmayı diğerlerinden ayıran özelliktir.

\section{Literatür Taraması}

Yapılan literatür taramasında hem volatilite hem de RMD analizi için bazı çalışmalar aşağıda sunulmuştur.

Angelidis, Benos ve Degiannakis (2004) çalışmalarında, beş hisse senedinden oluşan portföy üzerinde ARCH model ile riske maruz değer analizi yapmışlardır. İlk olarak, leptokurtik dağıtımların daha iyi RMD tahminleri üretebildiğini, ikinci olarak, örneklem büyüklüğünün seçiminin tahminin doğruluğu için önemli olduğunu ve üçüncü olarak, en doğru tahminleri üreten ARCH yapısı her portföy için farklı ve her hisse senedi endeksine özel olduğunu bulmuşlardır.

Altaylıgil (2008) çalışmasında, 18 Kasım 2005-28 Mart 2008 dönemi altın verilerini kullanarak değişen varyansı EWMA ve GARCH yöntemleriyle analiz etmiş ve RMD değerlerini karşılaştırmıştır. Sonuç olarak, Monte Carlo yönteminin Varyans Kovaryans yöntemine göre daha güvenilir olduğunu ve GARCH modelinin dönem boyunca değişen varyansı daha güvenilir tahmin etmesine karşın EWMA modelinin son dönemde altın fiyatlarında meydana gelen değişimlere karşı daha duyarlı davrandığını belirtmiştir.

Atakan (2009) çalışmasında, volatilitenin modellenmesinde İMKB-Bileşik 100 Endeksinin 19872008 dönemi günlük kapanış değerlerini kullanarak en uygun ARCH ailesi modeli araştırmıştır. Sonuç olarak, en uygun yöntemin GARCH $(1,1)$ modelin olduğunu ve kriz zamanlarında değişkenliğin arttı̆̆ ve volatilite kümelenmelerinin oluştuğunu belirtmiştir.

Kendirli ve Karadeniz (2012) çalışmalarında, İMKB 30 endeksinde ARCH tipi değişen varyans modellerinden GARCH $(1,1)$ modeli kullanarak analiz etmiştir. Çalışma sonucunda, varyans kırılmaların dikkate alan yatırımcı için katkı sağlayacağı bulgusuna ulaşmışlardır.

Cera, Cera ve Lito (2013) çalışmalarında, GARCH modeli kullanarak diğer para birimlerinin sabit kalması koşuluyla Euro para biriminin 1 Ocak 2002-20 Haziran 2013 dönemini içeren RMD analizi yapmışlardır. GARCH modelin uygun model olduğuna ve döviz kuru volatilite lere maruz kalan bireylere ve işletmelere hizmet edebileceği sonucuna ulaşmışlardır. 
Avşarlıgil, Demir ve Doğru (2015) çalışmalarında, riske maruz değeri hesaplamada varyanskovaryans, tarihsel simülasyon ve EWMA yöntemlerini kullanarak, BIST'teki spor kulübü hisselerinden iki farklı sanal portföy oluşturarak incelemişlerdir. Analiz sonucunda sabit varyans ve normal dağılımı için en etkili tahminlemeyi varyans-kovaryans yönteminin yaptığı sonucuna ulaşmışlardır.

Koima, Mwita ve Nassiuma (2015) çalışmalarında, Kenya hisse senedi piyasalarının borsa volatilitesini GARCH modellerini kullanarak incelemişlerdir. Sonuç olarak, bir mali krizde negatif getiri şokların, pozitif getiri şoklarından daha yüksek volatiliteye sahip olacağını belirtmişlerdir.

Işıklar (2016) çalışmasında, XU100 endeksi üzerinde volatilite analizinde kullanılan koşullu varyans modellemesi ve model öngörü performans analizi yapmıştır. Sonuç olarak, ekonomideki şoklardan İMKB'nin de etkilendiğini ve şokların volatilite neden olduğunu belirtmiştir.

Babacan (2017) çalışmasında, devlet tahvili, hisse senedi, hazine bonosu ve vadeli mevduatı içeren sermaye araçlarıyla oluşturulan portföyle varyans-kovaryans yöntemi ve standart riske maruz değer yöntemi karşılaştırması analizi yapmıştır. Sonuç olarak, varyans-kovaryans yöntemi ile oluşturulan portföyün, varlıkların tekil olarak değerlendirildiği standart riske maruz değer yöntemine göre daha az riskli olduğunu belirtmiştir.

Belasri ve Ellaia (2017) çalışmalarında, Fas hisse senedi piyasalarında 10 yıllık günlük hisse senedi fiyatlarıyla varyans kovaryans matrislerini tahmin etmek için çok değişkenli GARCH modellerinin performansını dinamik koşullu korelasyon (DCC) ve Baba, Engle, Kraft ve Kroner (BEKK) modelleri aracılığıyla incelemișlerdir. Sonuç olarak, BEKK modelinin varyans kovaryans matrislerini modellemede DCC'den daha iyi performans gösterdiğini ve her iki modelin de RMD'yi yeterince tahmin edemediğini belirtmişlerdir.

Cihangir ve Uğurlu, (2017) çalışmalarında, İstanbul Altın Piyasası (ABD Doları/Ons) 01.01.201028.10.2016 dönemi günlük verileri üzerinde APARCH, TARCH ve EGARCH ve GARCH modellerini kullanarak volatilite analizi yapmışlardır. Sonuç olarak, en uygun modelin APARCH model olduğu ve altın fiyatlarındaki volatilitenin olumlu şoklardan daha fazla etkilendiği belirtmişlerdir.

Çekici (2017) çalışmasında, Borsa İstanbul'daki 5 sigorta şirketinin 253 günlük veri kullanarak delta normal/varyans kovaryans yöntemiyle RMD ölçümlemesi yapmıştır. Çalışma sonucunda, \%1 olasılıkla 1 yılda en fazla \%33,9 oranında 1694,47 TL değer kaybedeceğini ve yüksek risk taşıdıkları bulgusuna ulaşmıştır.

Dalbudak vd. (2017) çalışmalarında, İMKB 30'da farklı kriterlere göre oluşturulan portföy üzerinde Tarihsel Simülasyon, Varyans-Kovaryans ve Monte Carlo Simülasyonu Yöntemleri kullanarak RMD analizi yapmışlardır. Sonuç olarak, volatilite kriterine göre portföy-2 en düşük RMD değerini vermiştir. Varyans-Kovaryans ve Monte Carlo Simülasyonu Yöntemleri aynı sonuçları verirken Tarihsel Simülasyon yöntemi yüksek sonuç vermiştir. Yatırımcıların tercih sıralamasında Tarihsel Simülasyon yöntemini üst sırada tutmaları önerilmiştir.

Şencan (2017) çalışmasında, 2012-2015 tarihlerinde BIST altın endeks getiri volatilitesi için en uygun koşullu değişen varyans modelini belirlemeye çalışmıştır. En iyi yöntemin $\operatorname{GARCH}(1,1)$ model olduğu sonucuna ulaşmıştır.

Uğur ve Bingöl (2017) çalışmalarında, 2003- 2016 yıllarında Borsa İstanbul imalat sanayi hisse senetlerinden oluşan 6 adet portföyün 1 günlük, 10 günlük ve 21 günlük riske maruz değerini VaryansKovaryans yöntemiyle karşılaştırmışlardır. Sonuç olarak, farklı sektörlerin hisse senetlerinden oluşan portföyün kaybının daha düşük olduğunu belirtmişlerdir.

Akbulaev ve Aliyeva (2018) çalışmalarında, vadeli işlemler ve opsiyon borsasında EURO/TL, USD/TL ve altın sözleşme fiyatları kullanarak oluşturdukları portföy üzerinde riske maruz değer analizi 
yapmışlardır. Sonuç olarak, portföy oluşturmanın riski en aza indirebileceğini ve sürenin uzamasıyla RMD değerin de yüksek olacağını belirtmişlerdir.

Aridi, Cheong ve Hooi (2018) çalışmalarında, Malezya'daki hem geleneksel hem de İslami borsalar için RMD değerlendirmesinde GARCH modellerle volatilite tahmininin doğru olup olmadığını araştırmışlardır. Borsa getirilerinde koşullu varyansı modellemesi için normal ve -t dağılımlı GARCH $(1,1)$, TGARCH $(1,1)$ ve CGARCH $(1,1)$ volatilite modellerini kullanmışlardır. Akaike Bilgi Kriterine (AIC) göre, en iyi modelin TGARCH $(1,1)$ modeli olduğunu ve geriye dönük test sonuçlarında da normal dağılımın student-t dağılımına göre daha iyi sonuçlar verdiğini belirtmişlerdir.

Bilir ve Aslan (2019) çalışmalarında, BIST-100 Endeksinde 30 adet hisse senedinden oluşturdukları hipotetik portföy ile yatırımcıların karşılaşabilecekleri riskler ve bileşenlerini sıralayarak göstermeye çalışmışlardır. Sonuç olarak, sistematik olmayan risklerin daha fazla oranda yer aldığı ve aynı sektör içindeki işletmelerin benzer riskler taşıdıklarını ama sektörel bazda farklılaşan bir risk ayrımının olmadığını belirtmişlerdir.

Bayçelebi ve Ertuğrul (2020) çalışmalarında, 2010-2016 arası BIST Banka (XBANK) endeks volatilitesini GARCH, TGARCH ve EGARCH koşullu varyans modelleri kullanarak modellemişlerdir. Sonuç olarak, uygun modelin GARCH $(1,1)$ modeli olduğunu belirterek çözümlemişlerdir.

\section{Yöntem}

\section{Çalışmanın Kapsam ve Amacı}

Çalışmanın kapsamı, altın (TL/Kg), Bist 100 endeksi ve Amerikan Doları'ndan oluşan eşit paya sahip hipotetik bir portföydür. Çalışmanın amacı, bir portföy üzerinde RMD analiziyle portföy riskini ölçmektir. Asimetrik GARCH modeller kullanarak Altın, Bist 100 endeksi ve Dolar serileri üzerinde koşullu RMD değerler ile RMD portföy değerleri karşılaştırılarak risk ölçümü gerçekleştirilmiştir.

\section{Veriler ve Değişkenler}

Portföydeki varliklara ait 05/01/2010-10/06/2021 tarihler aras1 veriler kullanılmıştır. Bist 100 endeksi ve Dolar'a ait 2875 iş günü kapanış verileri Türkiye Cumhuriyet Merkez Bankası Elektronik Veri Dağıtım Sistemi’nden (EVDS) elde edilmiştir. Altına ait 2875 iş günü kapanış verileri ise, Borsa İstanbul veri tabanından elde edilmiştir. Hesaplamalarda Eviews12 ve Excel yazılımı kullanılmıştır.

Finansal zaman verileri durağan olmayan ve trend içeren verilerdir (Yıldırtan, 2017:243). Trendi gidermek için basit aritmetik getiri veya logaritmik getiri oranları kullanılmaktadır. Basit aritmetik getiri oranı aşağıdaki 4 nolu formül ile hesaplanabilir (Campbell, Lo ve MacKinlay, 998:9; Hung, Yang, Zhao, ve Lee 2018:360).

$$
R_{t}=\frac{p_{t}}{p_{t-1}}-\mathbf{1}
$$

Burada $R_{t}$ endeksin aritmetik getirisini, $p_{t}$ endeksin $t$ günündeki değerini ve $p_{t-1}$ endeksin önceki gün değerini göstermektedir. Orijinal veriler trend içerdikleri için basit aritmetik getiri oranları hesaplanarak trendden kurtarılmıştır. Getiri oranlarının hesaplanmasıyla trendin giderildiği Grafik 1'de görülmektedir. 
Grafik 1: Portföydeki Serilerin Orijinal ve Getiri Grafikleri
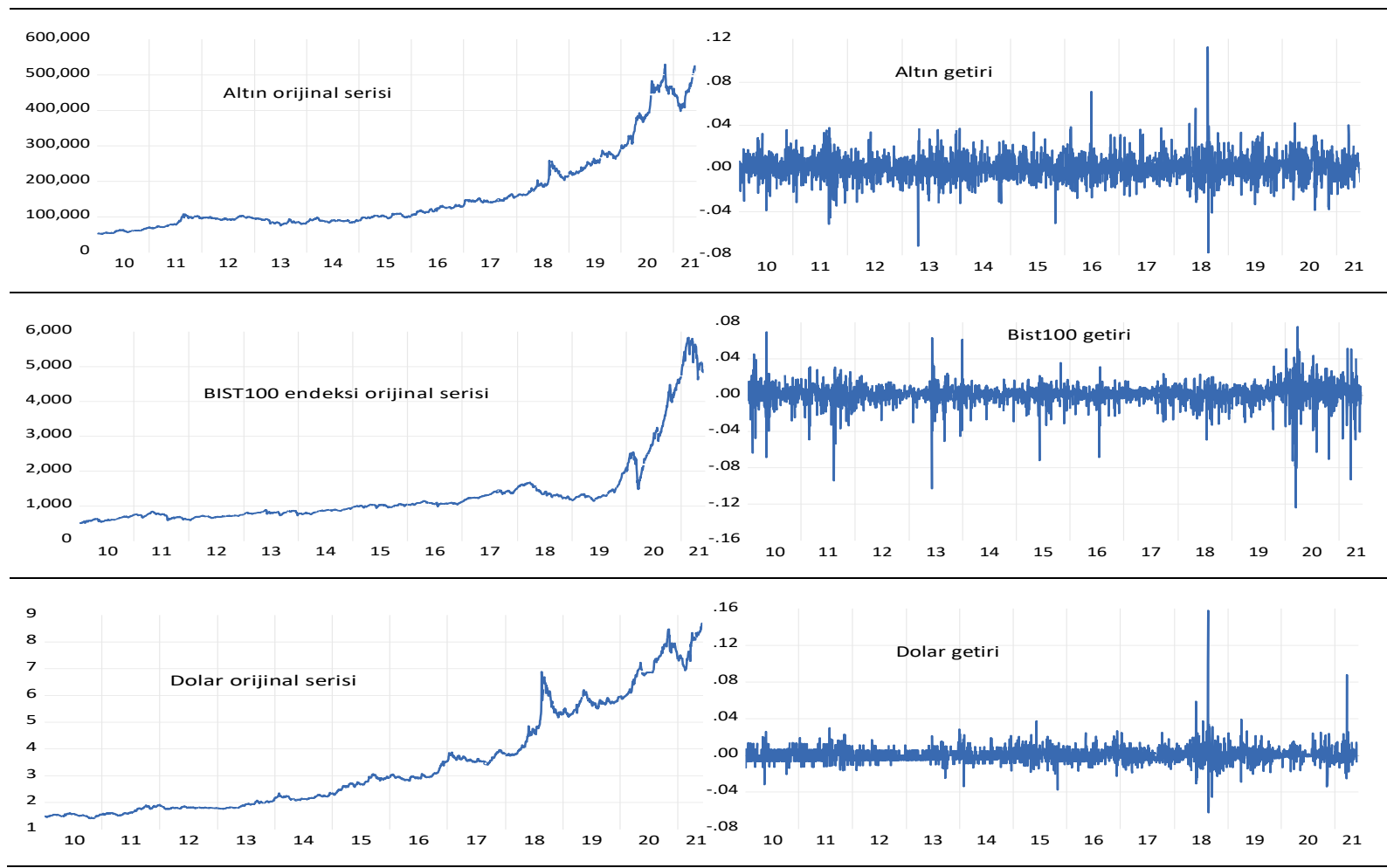

\section{Kullanılan Yöntemler}

RMD, Basel komitesi tarafından piyasa riskinin ölçülmesinde gelişmiş bir yöntem olarak önerilmekte ve risk ölçümünde yaygın olarak kullanılmaktadır (Basel Committee on Banking Supervision, 2016:17). RMD, portföyün beklenen minimum kâr seviyesini koruyarak maksimum zarar seviyesini ölçer (Babat, Vera ve Zuluaga 2018:305). RMD, belirli bir süre ve güven düzeyinde finansal varlıkların karşılaşacakları kazanç veya kayıpları ölçer (Fernandez, 2009:464). Dolayısıyla karşılaşılabilecek en fazla zararın ne olacağının bir tahminini verir. Kesin bir kayıp tutarı sunmamaktadır. RMD, Varyans-Kovaryans Yöntemi (Parametrik Yöntem), Tarihi simülasyon Yöntemi ve Monte Carlo Simülasyonu yöntemi olarak üç temel yöntemle ölçülmektedir (Munniksma, 2006:14; Echaust, 2019:45; Altıntaş, 2006:220).

RMD, tarihi verileri kullanan parametrik bir yöntemdir (Echaust, 2019:45). Parametrik yöntemler ana kütle hakkında fazla bilgi olmadığında kullanılırlar. Parametrik yöntemlerde kullanılan veriler, bağımsız (rassal seçilmiş) olmalı, normal dağılmalı, sabit varyanslı ve eşit aralıklı olmalıdır (Karagöz, 2016:351; Wipplinger, 2007:122).

Parametrik testlerin doğru sonuçlar üretmesi serilerin durağan olmasına bağlıdır (Gujarati, 2015:233). Durağan olmayan zaman serileriyle analiz yapıldığında sahte regresyonla karşılaşılabilir. $\mathrm{Bu}$ durumda, F ve t istatistikleri gibi temel istatistiklere güvenilmez (Boğa, 2020:46). Durağanlık testi için genellikle Augmented Dickey Fuller (ADF) birim kök testi yapılabilir (Gujarat1, 2015:266).

Parametrik testlerin bir diğeri varsayımı da varyansın sabit olmasıdır. Sabit varyans, gözlemlerin varyansının değişmemesi aynı kalmasıdır (Güriş, Çağlayan ve Güriş 2013:255). Varyanslar değişkenliğe sahipse, gerçek değerlerinden sürekli uzaklaşacaktır. Bu durumda, varyans sapmalı 
olduğundan değerler daha büyük veya küçük tahmin edilirler. Varyansın değişmesi heteroskedastisite olarak adlandırılmaktadır. Finansal zaman serileri çoğunlukla heteroskedastisite ve otokorelasyon özelliğine sahiptirler (Kellner ve Rösch, 2016:45). Heteroskedastisite olup olmadığının belirlenmesinde genellikle Goldfeld-Quandt test, Park test, Glejser test, Breusch-Pagan test, White test ve Benzerlik Oranı testi kullanılmaktadır.

Parametrik testlerin bir diğer varsayımı da değişkenler arasında otokorelasyon olmamasıdır. Otokorelasyon, değişkenler arasındaki ilişkiyi gösterir (Güriş vd., 2013:199). Verilerde otokorelasyon olup olmadığının belirlenmesinde genellikle grafik yöntem, Durbin-Watson d-istatistiği, BreuschGodfrey LM testi gibi testler yapılabilmektedir.

Parametrik testlerin en önemli varsayımı verilerin normal dağılım göstermesidir. Normal dağılım, sürekli ve simetrik dağılım gösterir (Karagöz, 2016:91; Çil Yavuz, 2015:34). RMD hesaplamaları, finansal varlıkların getirilerinin normal dağıldığı varsayımı altında yapılan bir istatistiktir (Çil Yavuz, 2015:28). Verilerin normal dağılıp dağılmadığının ölçülmesinde genellikle Jarque-Bera testi ve Kolmogorov-Smirnov testleri birlikte kullanılmaktadır (Ghasemi ve Zahediasl, 2012:487).

Ancak finansal zaman serileri kalın kuyruk ve aşırı sivri (leptokörtisis) özelliklerinden dolayı normal dağılım eğilimi göstermezler (Çil Yavuz, 2015:39; Krokhmal, Palmquist ve Uryasev 2002:44). Finansal verilerin normal dağılım göstermemesi durumunda RMD yerine koşullu RMD kullanılmaktadır (Rockafellar ve Uryasev, 2000:21). Koşullu RMD, verilerin normal dağılmamasından kaynaklanan beklenen kaybı (Expected Shortfall) ölçer. Beklenen kayıp, RMD'yi aşan zararların ortalamasıdır ve normal RMD değerinden yüksektir (Türker, 2009:10). Koşullu RMD, \%95 güven düzeyinde \%5'lik beklenen kayıpların ortalamasıdır (Andersson, Mausser, Rosen ve Uryasev, 2001:274). Koşullu RMD, ortalama riske maruz değer (average value-at-risk), kuyruk değerli riske maruz değer (tail value-at-risk) ve beklenen kayıp olarak da bilinmektedir (Elçi ve Noyan, 2018:61). Sonuç olarak, koşullu RMD, RMD'den daha tutarlı bir risk ölçüsü olarak kabul edilmektedir.

Finansal varlık risk ölçümünde, volatilite bir ölçüt olarak kullanılmaktadır (Berggren, 2014:1). Volatilite, bir finansal varlığın fiyat değişikliklerinin istatistiksel ölçütüdür (Butler, 1999: 190). Volatilitenin hesaplanmasında, standart sapma veya varyans kullanılmaktadır (Çil Yavuz, 2015:424). Varyans standart sapmanın karesidir. Standart sapma, verilerin ortalamadan sapmalarının karelerinin ortalamasıdır. Volatilitenin doğru hesaplanabilmesi için Basel Komitesi tarafından önerilen en az 250 iş günü değerin hesaplanması gerekmektedir (Longerstaey, 1996:250). Standart sapmanın güvenirliliği verilerin büyüklügüyle doğru orantılıdır. Örneklem veri sayısı arttıkça standart sapma küçülür ve ana kütle güvenirliği artar. Dolayısıyla finansal varlık riskin hesaplanmasında örneklem sayısı önem arz etmektedir (Karagöz, 2016:79).

Finansal zaman serilerinde zamanla değişen volatilite kümelenmeleri oluşabilir. $\mathrm{Bu}$ volatilite kümelenmelerini yakalamak için Engle (1982) ardışık bağımlı koşullu değişen varyans (Autoregressive Conditional Heteroscedastic-ARCH) modelini geliştirmiştir. ARCH model, 2 nolu formül ile hesaplanmaktadır.

$$
h_{t}=\omega+\sum_{i=1}^{p} \alpha_{i} \varepsilon_{t-1}^{2}
$$

ARCH model, Bollerslev (1986) tarafından geliştirilerek GARCH model oluşturulmuştur. GARCH modeline ait koşullu varyans $\left(h_{t}\right) 3$ nolu formül ile aşağıda gösterilmiştir

$$
h_{t}=\omega+\sum_{i=1}^{q} \alpha_{i} \varepsilon_{t-1}^{2}+\sum_{i=1}^{p} \beta_{j} h_{t-1}
$$

$$
\begin{array}{cccc}
\text { Burada } \alpha_{0}>0, \alpha_{i} \geq 0, \beta_{i} \geq 0 \text {, ve } \alpha_{1}+\beta_{1}<1 \text { olmalıdır. GARCH modelde negatif olmama } \\
\text { ve } & \text { büyük } & \text { olmama } & \text { kisitı }
\end{array}
$$


$p \geq 0, q>0, \omega>0, \alpha_{i} \geq 0, i=1, \ldots q \beta \geq 0, i=1, \ldots p$ olmalıdır. $P=0$ olursa, formül sadece ARCH sürecini $\left(h_{t}=\omega+\sum_{i=1}^{q} \alpha_{i} \varepsilon_{t-1}^{2}\right)$ içerir (Poon 2005:38).

Normal dağılım göstermeyen finansal varlıkların volatilitenin ölçümünde birçok GARCH model kullanılmaktadır. Türetilmiş GARCH modellerinden en çok kullanılanları şunlardır.

Bu GARCH modellerinden birisi, Zakoian'ın (1994) kaldıraç etkisi ekleyerek geliştirdiği iyi ve kötü haber etkisini ayrıștırıcı parametrelerin kullanıldığı TGARCH (Threshold GARCH) modelidir. TGARCH asimetrik bir model olup, aşağıdaki 4 nolu formül kullanılarak hesaplanabilir.

$h_{t}=\omega+\sum_{i=1}^{p}\left(\alpha_{i}+\gamma_{i} I_{t-1}\right) \alpha_{t-1}^{2}+\sum_{i=1}^{p} \beta_{j} h_{t-1} \quad I_{t-1}= \begin{cases}1, & \alpha_{t-1}<0 \text { kötū haber } \\ 0, & \alpha_{t-1} \geq 0 \text { iyi haber }\end{cases}$

Formülde, $\alpha_{i}, \gamma_{i}$ ve $\beta_{j}$ benzer koşulları sağlayan negatif olmayan parametrelerdir. $\gamma_{i}$ kaldıraç parametresidir. $\gamma_{i}$ parametresi $\gamma_{i} \neq 0$ olması durumunda asimetriklik söz konusu olur ve sıfıra eşit olması durumunda model, GARCH model olur (Babaşova, 2012:51). Model, geçmiş şokların etkilerini ayırmak için eşik değer olarak sıfırı kullanır. Pozitif $\alpha_{t-i}, \alpha_{i}{ }^{6}$ ya katkıda bulunurken negatif $\alpha_{t-i}$ ise, $\left(\alpha_{i}+\gamma_{i}\right) \alpha_{t-i}^{2}$ üzerinde daha büyük bir etkiye sahiptir. Eğer $\gamma_{i}>0$ ise, kötü haberlerin etkisi daha da büyük olacaktır. Buna kaldıraç etkisi denilmektedir (Cihangir ve Uğurlu, 2017:289).

Diğer bir GARCH model Nelson (1991) tarafından geliştirilen EGARCH (Exponential GARCH) modeldir. Negatif olmama ve büyüklük kısıtlarını sağlayacak şekilde oluşturulan EGARCH modelinin genel kullanımı aşağıdaki 5 nolu formül ile gösterilmiştir.

$$
\ln h_{t}=\omega+\sum_{j=1}^{p} \beta_{j} \ln h_{t-1}+\sum_{i=1}^{p} \alpha_{i}\left|\frac{s_{t-1}}{h_{t-1}}\right|+\sum_{i=1}^{p} \gamma_{i} \frac{s_{t-1}}{h_{t-1}}
$$

Koşullu varyansın logaritması alınarak oluşturulan EGARCH modeli asimetrik bir modeldir. Katsayının anlamlı olması asimetrikliğin varlığını ve $\gamma_{\mathrm{i}} \neq 0$ olması asimetrik etkinin olduğunu gösterir (Çil Yavuz, 2015:463). Logaritmik dönüşüm yapıldığı için parametreler negatif olsa bile koşullu varyans pozitif olacaktır. $\beta$ parametresi volatilite sürekliliği ölçer. $\alpha$ etkinin yönünü belirlerken $\gamma$ etkinin boyutunu ölçer. $\gamma$ parametresi $\gamma>0$ ise, ortalamanın üzerindeki şoklar volatiliteyi artıracaktır. $\gamma$ parametresi $\gamma<0$ ise, pozitif şokların etkisi negatif şokların etkisinden daha az olacaktır.

Diğer bir GARCH modeli ise, Ding, Granger ve Engle (1993) tarafindan tanıtılan standart sapma modeli Asimetrik Power ARCH (APARCH) modelidir. APARCH model aşağıdaki 6 nolu formülle hesaplanabilir.

$$
\sigma_{t}^{\delta}=\omega+\sum_{j=1}^{q} \beta_{j} \sigma_{t-j}^{\delta}+\sum_{i=1}^{p} \alpha_{i}\left(\left|\varepsilon_{t-i}\right|-\gamma_{i} \varepsilon_{t-i}\right)^{\delta}
$$

Burada, $\gamma$, kaldıraç ve $\delta$ ise, güç parametresidir. $\gamma=0$ durumunda simetrik etki ve $\gamma \neq 0$ durumunda asimetrik etki görülür. APARCH modelde $\alpha_{0}>0, \alpha_{1} \geq 0, \beta \geq 0$ ve $1 \geq \alpha+\beta \geq 0$ kısıtları sağlanmalıdır.

GARCH modeline göre hesaplanan volatilite RMD hesaplamasında kullanılabilir. RMD ile finansal varlık üzerinden sağlanacak en düşük getiri veya katlanılacak en fazla zarar hesaplanmış olur. Finansal varlığın RMD değerinin hesaplanmasında 7 nolu denklem kullanılmaktadır (Best 2000:23; Terzioğlu, 2018:50).

$\mathrm{RMD}=\mathrm{Z}_{\mathrm{\alpha}} * \sigma * \sqrt{\mathrm{T}}$

$\mathrm{Z}_{\alpha}=\mathrm{Z}$ değeri (standart normal dağ 11 ım tablosu değeri)

$\sigma=$ Getirinin standart sapmas1 (Volatilite)

$\sqrt{\mathrm{T}}=$ Elde bulundurma süresini göstermektedir. 
Finansal varlıklardan oluşan portföyün riske maruz değerinin (RMDp) hesaplanmasında ise (8) nolu formül kullanılmaktadır (Engle, 2002:341; Best 2000:23; Moran, 2017:410; Lebo, 2008:694; Dowd 1999:47).

$$
\mathrm{RMDp}=\sqrt{V * C * V^{T}}
$$

$\mathrm{V}=$ Her bir varlık için ayrı ayrı hesaplanan RMD değerin yatay matrisi

$\mathrm{C}=$ Portföydeki varlıkların korelasyon matrisi

$V^{T}=$ Her bir varlık için ayrı ayrı hesaplanan RMD değerin transpose (dikey) matrisini ifade etmektedir.

\section{Bulgular}

Finansal zaman serileriyle RMD analizi yapılabilmesi için bazı varsayımların sağlanması gerekir. $\mathrm{Bu}$ varsayımlara adım adım aşağıda yer verilmiştir:

Finansal zaman serileri durağan olmalıdır (Gujarati, 2016:319). Finansal zaman serisinin durağan olup olmadığının belirlenmesinde Augmented Dickey-Fuller (ADF) birim test istatistiği, KwiatkowskiPhillips-Schmidt-Shin (KPSS) test ve grafik gibi yöntemler kullanılmaktadır (Sarıkovanlı, Koy, Akkaya, Yıldırım ve Kantar 2018:111). ADF test istatistiğine ait sonuçlar Tablo 1'de verilmiştir.

Tablo 1: Augmented Dickey-Fuller Test Statistic (Durağanlık Testi)

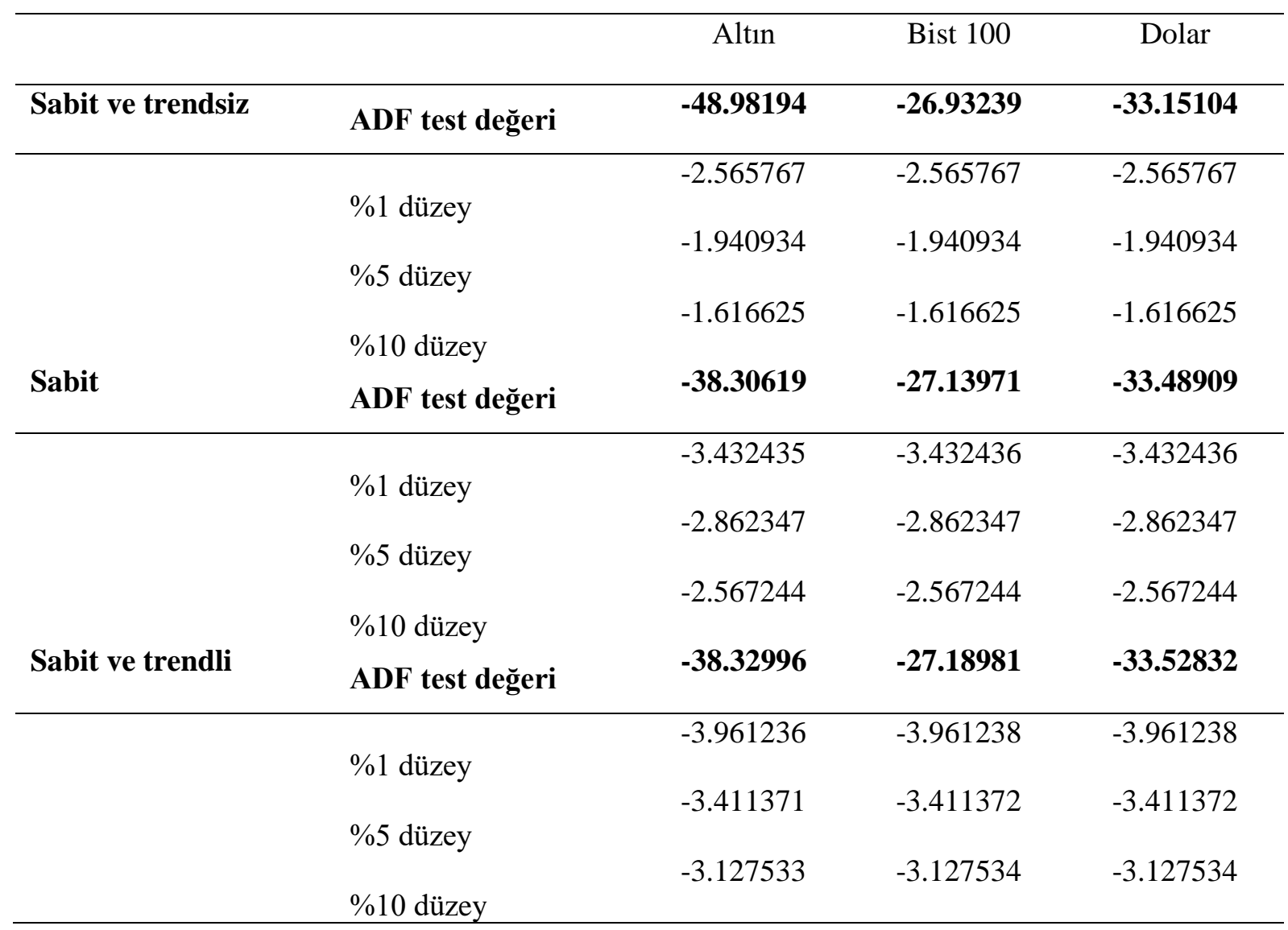

Serilerin sabit ve trendsiz, sabit ve sabit ve trendli test değerlerine göre ADF test değeri $\% 1, \% 5$ ve \%10 düzey değerlerinden daha küçük olduğu için durağandır. Yani, birim kök içermediği görülmüştür. 
Finansal zaman serileri aynı zamanda normal dağılım göstermelidir. Serilerin normal dağılım gösterip göstermediğinin belirlenmesinde Jarque-Bera, Skewness ve Kurtosis değerleri kullanılmaktadır (Güriş vd., 2013:298). Portföyde kullanılan finansal zaman serisi istatistik bilgileri ve normal dağılım değerleri Grafik 2'de sunulmuştur.

Grafik 2: Betimsel İstatistikler, Jarque-Bera, Skewness ve Kurtosis Değerleri.

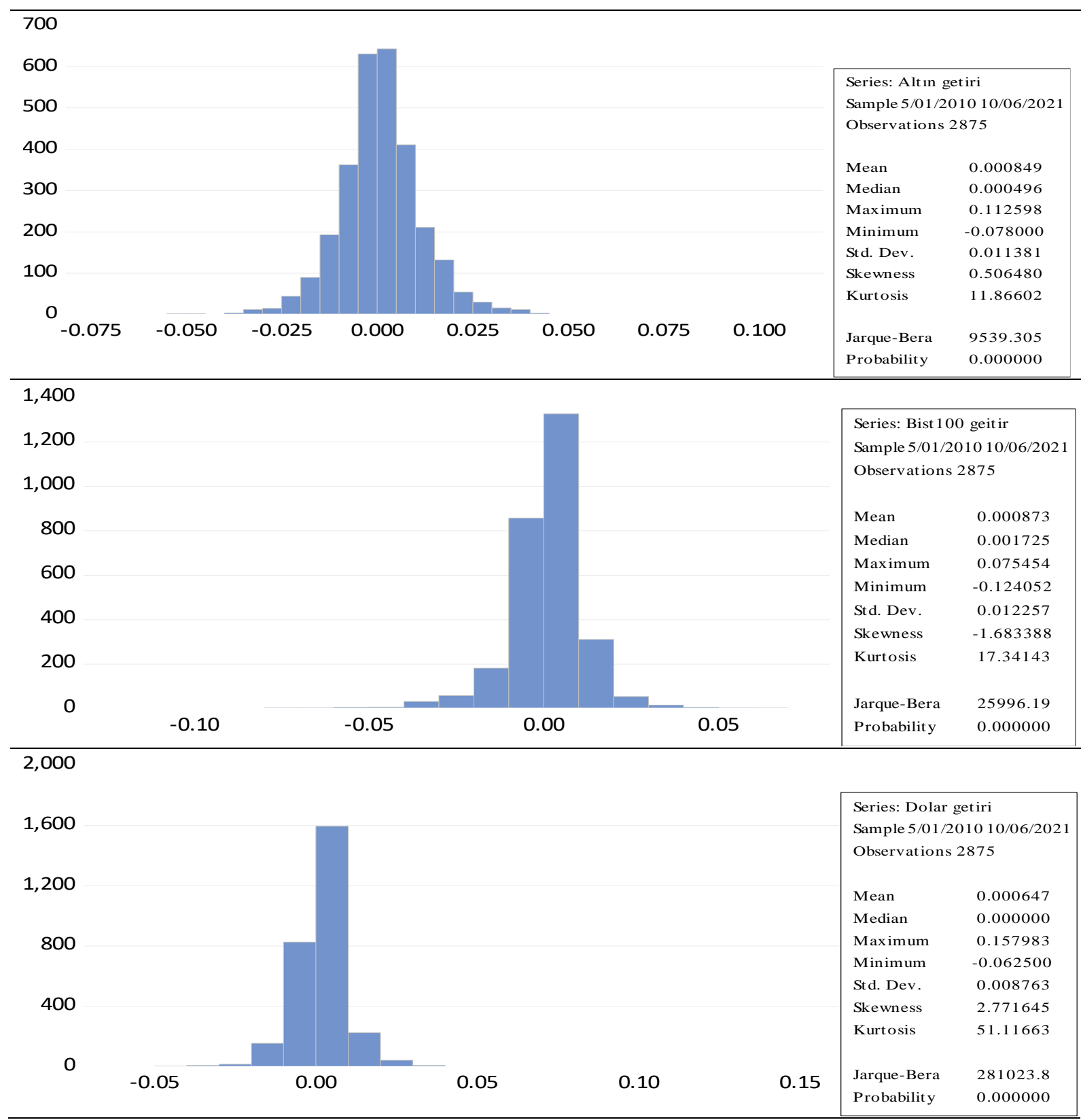

Jarque-Bera testi değeri 5,99'un altında olmalıdır. Altın, Bist 100 ve Dolar değerleri 5,99'un çok üzerindedir. Skewness ve Kurtosis değerleri \pm 1 sınırları içinde olmalıdır. Altın, Bist 100 ve Dolar serileri istatiksel olarak anlamsız ve Kurtosis değerleri \pm 1 sınırları dışındadır. Bu seriler normal dağılım göstermemekte olup doğrusal olmayan bir yapıdadır. Normal dağılım göstermeyen bu serilerle analiz yapmak riskin dağıtılmasında ve kayıpların düzeyinin belirlenmesinde doğru sonuçlar vermeyecektir. 
Finansal zaman serilerinin normal dağılım göstermemesi çoğu yayında genel kabul görmüştür. Normal dağılım göstermeyen finansal varlıkların volatilitesinin ölçümünde Engle (1982), sakıncaları kısmen bertaraf eden doğrusal olmayan ARCH modelini geliştirmiştir. ARCH modellerle sadece hatalar arasındaki ardışık bağımlılık değil aynı zamanda hata varyanslarındaki değişimler de test edilmektedir.

Finansal zaman serilerinde otokorelasyon olmamalıdır. Altın, Bist 100 ve Dolar serilerinin otokorelasyonlu olup olmadığını belirleyebilmek için Breusch-Godfrey Serial Correlation LM test yapılarak Tablo 2'de gösterilmiştir.

Tablo 2: Breusch-Godfrey Serial Correlation LM Testi

\begin{tabular}{lccc}
\hline & Altın & Bist 100 & Dolar \\
\hline F-statistic & 14,84554 & 18,34382 & 13,45164 \\
Prob. F & $(0,0000)$ & $(0,8871)$ & $(0,0000)$ \\
Obs*R-squared & 29,41797 & 36,26273 & 26,68145 \\
Prob.Chi-Square & $(0,0000)$ & $(0,8870)$ & $(0,0000)$ \\
\hline
\end{tabular}

Tablo 2'de görüleceği üzere olasılık değeri (Prob. değerleri >0.05) büyük olduğu için Bist 100 serisinde otokorelasyon yoktur. Altın ve Dolar serilerinde olasılık değeri (Prob. değerleri $<0.05$ ) küçük olduğu için otokorelasyon vardır.

Finansal zaman serileri sabit varyanslı olmalıdır. Altın, Bist 100 ve Dolar serilerinde heteroskedastisite olup olmadığını belirleyebilmek için Breusch-Pagan-Godfrey Heteroscedasticity LM testi sonuçları Tablo 3'te sunulmuştur.

Tablo 3: Breusch-Pagan-Godfrey Testi

\begin{tabular}{lccc}
\hline & Altin & Bist 100 & Dolar \\
\hline F-statistic & 69.46491 & 602.7325 & 520.1043 \\
Prob. F & $(0.0000)$ & $(0.0000)$ & $(0.0000)$ \\
Obs*R-squared & 67.87222 & 498.5585 & 440.6879 \\
Prob. Chi-Square & $(0.0000)$ & $(0.0000)$ & $(0.0000)$ \\
Scaled explained SS & 368.4941 & 4070.745 & 11035.21 \\
Prob. Chi-Square & $(0.0000)$ & $(0.0000)$ & $(0.0000)$ \\
\hline
\end{tabular}

Tablo 3 ’te görüleceği üzere olasılık değeri (Prob. değerleri<0.05) küçük olduğu için Altın, Bist 100 ve Dolar serilerinde heteroskedastisite vardir.

Yapılan istatistik analiz testleri sonucunda serilerin normal dağılmaması ve değişen varyansa sahip olması nedeniyle RMD analizi doğru sonuçlar üretmeyecektir. Dolayısıyla RMD analizinde Bollerslev (1986) koşullu varyansı ARMA (Otoregresif Hareketli Ortalama) süreci ile modellediği Genelleştirilmiş Otoregresif Koşullu Varyans (GARCH) modeliyle volatilite hesaplanmış daha sonra RMD analizi yapılmıştır.

ARMA süreci çalıştırılarak hangi GARCH tipi modelin kullanılacağına karar verilmiştir. ARMA sürecinde, En Küçük Kareler Yöntemi (EKK) kullanılmaktadır (Kutlar ve Torun 2013:9). EKK yöntemine göre uygun ARMA model seçilmesi sürecin ilk aşamasını oluşturmaktadır. Daha sonra ARMA modelde ARCH etkisi test edilmelidir. ARCH etkisi varsa GARCH modeli kurulabilir. Uygun ARMA model kullanılarak uygun GARCH modeli seçimi yapılmalıdır. Sonuç olarak, uygun GARCH modeli seçiminden sonra RMD hesaplaması yapılmıştır. 
Uygun ARMA modellerin belirlenmesinde 1-4'e kadar yapılan denemelerden \%1 düzeyde anlamlı olan modellerin en küçük AIC, SIC ve HQC ve en büyük Log Likelihood değere sahip olan modelleri seçilmiştir.

Altın ve Dolar için ARMA (3,1), Bist 100 için ARMA $(1,1)$ uygun model olarak belirlenmiştir. Bu ARMA modeller için ARCH etkisinin olup olmadığ 1 test edilmiş olup Tablo 4 'te gösterilmiştir.

Tablo 4: Altın, Bist 100 ve Dolar Serileri ARCH Testi

\begin{tabular}{llll}
\hline & Altın & Bist 100 & Dolar \\
\hline F-statistic & 598.3698 & 155.7803 & 564.9579 \\
Prob. F & $(0,0000)$ & $(0,0000)$ & $(0,0000)$ \\
Obs*R-squared & 495.5423 & 147.8683 & 472.4204 \\
Prob.Chi-Square & $(0,0000)$ & $(0,0000)$ & $(0,0000)$ \\
\hline
\end{tabular}

Tablo 4'te görüldüğü üzere Altın, Bist 100 ve Dolar serilerinde boş hipotez reddedilerek ARCH etkisi olduğu bulunmuştur. $\mathrm{Bu}$ durumda hangi GARCH tipi model kullanılabilir olduğu bulunmalıdır. Seçilen ARMA modelleri için GARCH modeller test edilerek Tablo 5'te verilmiştir.

Tablo 5: Altın, Bist 100 ve Dolar Serileri GARCH Model Seçimi Sonuçları

\begin{tabular}{|c|c|c|c|c|c|}
\hline & & GARCH & TARCH & EGARCH & PARCH \\
\hline \multirow{16}{*}{$\underset{⿱ 乛}{\stackrel{\Xi}{\rightleftarrows}}$} & $\omega$ & $2,48 \mathrm{E}-05$ & $2,15 \mathrm{E}-05$ & $-1,563528$ & 0,000183 \\
\hline & & $(0,0000)$ & $(0,0000)$ & $(0,0000)$ & $(0,2392)$ \\
\hline & $\alpha$ & 0,149941 & 0,201974 & 0,304581 & 0,177782 \\
\hline & & $(0,0000)$ & $(0,0000)$ & $(0,0000)$ & $(0,0000)$ \\
\hline & $\beta$ & 0,599941 & $-0,048668$ & 0,026265 & $-0,084956$ \\
\hline & & $(0,0000)$ & $(0,0035)$ & $(0,0035)$ & $(0,0071)$ \\
\hline & $\gamma$ & & 0,652532 & 0,852968 & 0,691289 \\
\hline & & & $(0,0000)$ & $(0,0000)$ & $(0,0000)$ \\
\hline & $\delta$ & & & & 1,504528 \\
\hline & & & & & $(0,0000)$ \\
\hline & R-squared & 0,006434 & 0,005961 & 0,005829 & 0,005894 \\
\hline & Sum Sequared Resid & 0,369760 & 0,369936 & 0,369985 & 0,369961 \\
\hline & Log likelihood & 8981,970 & 8997,182 & 8995,167 & 8999,173 \\
\hline & AIC & $-6,250676$ & $-6,260572$ & $-6,259169$ & $-6,261262$ \\
\hline & SIC & $-6,238219$ & $-6,246039$ & $-6,244636$ & $-6,244653$ \\
\hline & HQC & $-6,246185$ & $-6,255333$ & $-6,253930$ & $-6,255275$ \\
\hline \multirow{10}{*}{$\frac{8}{8}$} & $\omega$ & $1,13 \mathrm{E}-05$ & $1,18 \mathrm{E}-05$ & $-1,046138$ & 0,000590 \\
\hline & & $(0,0000)$ & $(0,0000)$ & $(0,0000)$ & $(0,0058)$ \\
\hline & $\alpha$ & 0,149914 & 0,108318 & 0,337065 & 0,212013 \\
\hline & & $(0,0000)$ & $(0,0000)$ & $(0,0000)$ & $(0,0000)$ \\
\hline & $\beta$ & 0,599914 & 0,276357 & $-0,117617$ & 0,446822 \\
\hline & & $(0,0000)$ & $(0,0000)$ & $(0,0000)$ & $(0,0000)$ \\
\hline & $\gamma$ & & 0,688740 & 0,912291 & 0,752897 \\
\hline & & & $(0,0000)$ & $(0,0000)$ & $(0,0000)$ \\
\hline & $\delta$ & & & & 1,122335 \\
\hline & & & & & $(0,0000)$ \\
\hline
\end{tabular}




\begin{tabular}{|c|c|c|c|c|c|}
\hline & R-squared & 0,011450 & 0,007113 & 0,012690 & 0,009495 \\
\hline & Sum Sequared Resid & 0,426681 & 0,428553 & 0,426146 & 0,427525 \\
\hline & Log likelihood & 8865,016 & 9183,595 & 9183,361 & 9196,054 \\
\hline & AIC & $-6,164938$ & $-6,385940$ & $-6,385777$ & $-6,393914$ \\
\hline & SIC & $-6,152489$ & $-6,371415$ & $-6,371252$ & $-6,377314$ \\
\hline & HQC & $-6,160450$ & $-6,380704$ & $-6,380541$ & $-6,387930$ \\
\hline \multirow{16}{*}{$\frac{\bar{\Xi}}{\stackrel{\circ}{\circ}}$} & $\omega$ & $2,53 \mathrm{E}-06$ & $2,24 \mathrm{E}-06$ & $-0,669233$ & $1,79 \mathrm{E}-05$ \\
\hline & & $(0,0000)$ & $(0,0000)$ & $(0,0000)$ & $(0,1350)$ \\
\hline & $\alpha$ & 0,156858 & 0,182161 & 0,253573 & 0,138546 \\
\hline & & $(0,0000)$ & $(0,0000)$ & $(0,0000)$ & $(0,0000)$ \\
\hline & $\beta$ & 0,815817 & $-0,080543$ & 0,063697 & $-0,202604$ \\
\hline & & $(0,0000)$ & $(0,0000)$ & $(0,0000)$ & $(0,0000)$ \\
\hline & $\gamma$ & & 0,831316 & 0,950862 & 0,848463 \\
\hline & & & $(0,0000)$ & $(0,0000)$ & $(0,0000)$ \\
\hline & $\delta$ & & & & 1,570971 \\
\hline & & & & & $(0,0000)$ \\
\hline & R-squared & 0,006662 & 0,006416 & 0,008504 & 0,007244 \\
\hline & Sum Sequared Resid & 0,218981 & 0,219036 & 0,218575 & 0,218853 \\
\hline & Log likelihood & 10070,39 & 10078,82 & 10077,30 & 10081,19 \\
\hline & AIC & $-7,008629$ & $-7,013805$ & $-7,012743$ & $-7,014758$ \\
\hline & SIC & $-6,996172$ & $-6,999272$ & $-6,998209$ & $-6,998149$ \\
\hline & HQC & $-7,004138$ & $-7,008566$ & $-7,007503$ & $-7,008771$ \\
\hline
\end{tabular}

Not: $\omega$, sabit katsayı; $\alpha$, ARCH katsayısı; $\beta$, GARCH katsayısı; $\delta$, koşullu standart sapma süreci gücü ve $\gamma$, isteğe bağlı bir eşik parametresidir. Parantez içindeki değerler olasıllk (p) değerlerini göstermektedir.

GARCH modeli seçiminde R-squared değerinin en yüksek olması, en küçük AIC, SIC ve HQC değerine sahip olmas1, SSR en küçük değere sahip olmas1, Log Likelihood en yüksek olmas1, parametrelerin anlamlı olması, parametre kısıt koşullarının sağlanması, varyans denklemi katsayılarının pozitif değerli olması ve bu katsayıların toplamlarının birden küçük olması kriterleri kullanılmaktadır (Sevüktekin ve Nargeleçekenler, 2006:258; Çabuk, Özmen ve Kökcen 2011:15). Modeller, bu seçim kriterlerine göre incelenmiştir. Kriterlere göre yapılan inceleme sonucunda altın ve Dolar serinde TARCH model, Bist 100 serisinde ise, PARCH uygun model olmuştur. Altın serisi için uygun TARCH modeli oluşturularak Tablo 6'da model çıtısı verilmiştir.

Tablo 6: Altın Serisi TARCH Model Çıktısı

\begin{tabular}{lllll}
\hline Variable & Coefficient & Std. Error & z-Statistic & Prob. \\
\hline $\mathrm{C}$ & 0,000835 & 0,000193 & 4,337696 & 0,0000 \\
$\mathrm{AR}(3)$ & $-0,038380$ & 0,020168 & $-1,903008$ & 0,0570 \\
$\mathrm{MA}(1)$ & 0,020474 & 0,022188 & 0,922774 & 0,3561 \\
\hline $\mathrm{C}$ & $2,15 \mathrm{E}-05$ & $2,32 \mathrm{E}-06$ & 9,288627 & 0,0000 \\
$\mathrm{RESID}(-1)^{\wedge} 2$ & 0,201974 & 0,014563 & 13,86902 & 0,0000 \\
RESID $(-1)^{\wedge} 2^{*}(\mathrm{RESID}(-1)<0)$ & $-0,048668$ & 0,016660 & $-2,921290$ & 0,0035 \\
GARCH(-1) & 0,652532 & 0,028031 & 23,27869 & 0,0000 \\
\hline R-squared & 0,005961 & \multicolumn{2}{c}{ Mean dependent var } & 0,000849
\end{tabular}




\begin{tabular}{lllr} 
Adjusted R-squared & 0,005268 & S.D. dependent var & 0,011385 \\
S.E. of regression & 0,011355 & Akaike info criterion & $-6,260572$ \\
Sum squared resid & 0,369936 & Schwarz criterion & $-6,246039$ \\
Log likelihood & 8997,182 & Hannan-Quinn criter. & $-6,255333$ \\
Durbin-Watson stat & 1,872927 & & \\
\hline
\end{tabular}

TARCH $=2,15121940676 e-05+0,201974236792$

* RESID $(-1)^{2}-0,0486678882478 * \operatorname{RESID}(-1)^{2} *(\operatorname{RESID}(-1)<0)$ $+0,652531774579 *$ GARCH $(-1)$

TARCH $=2,15 E-05+(0,201974 * 0,369659)+(-0,048668 * 0,000000)$ $+(0,652532 * 0,368416)=0,315086$

Volatilite $=\sqrt{0,315086}=\% 56,13$

Bist 100 serisi için uygun EGARCH modeli oluşturularak Tablo 7'de model çıktısı verilmiştir.

Tablo 7: Bist 100 Serisi PARCH Model Çıktısı

\begin{tabular}{|c|c|c|c|c|}
\hline Variable & Coefficient & Std. Error & z-Statistic & Prob. \\
\hline $\mathrm{C}$ & 0,000262 & 0,000331 & 0,792517 & 0,4281 \\
\hline $\operatorname{AR}(1)$ & 0,872834 & 0,030859 & 28,28427 & 0,0000 \\
\hline $\mathrm{MA}(1)$ & $-0,779889$ & 0,039292 & $-19,84850$ & 0,0000 \\
\hline $\mathrm{C}(4)$ & 0.000590 & 0.000214 & 2.759739 & 0.0058 \\
\hline$C(5)$ & 0.212013 & 0.011100 & 19.10021 & 0.0000 \\
\hline $\mathrm{C}(6)$ & 0.446822 & 0.039663 & 11.26551 & 0.0000 \\
\hline $\mathrm{C}(7)$ & 0.752897 & 0.011788 & 63.87228 & 0.0000 \\
\hline $\mathrm{C}(8)$ & 1.122335 & 0.077447 & 14.49170 & 0.0000 \\
\hline R-squared & 0,009495 & \multicolumn{2}{|c|}{ Mean dependent var } & 0,000869 \\
\hline Adjusted R-squared & 0,008805 & \multicolumn{2}{|c|}{ S.D. dependent var } & 0,012257 \\
\hline S.E. of regression & 0,012203 & \multicolumn{2}{|c|}{ Akaike info criterion } & $-6,393914$ \\
\hline Sum squared resid & 0,427525 & \multicolumn{2}{|c|}{ Schwarz criterion } & $-6,377314$ \\
\hline Log likelihood & 9196,054 & \multicolumn{2}{|c|}{ Hannan-Quinn criter. } & $-6,387930$ \\
\hline Durbin-Watson stat & 2,013754 & & & \\
\hline
\end{tabular}

$@ S Q R T(G A R C H)^{\wedge} 1,12233499281$

$$
\begin{aligned}
& =0,000590366153731+0,212012939392(\text { ABS }(\text { RESID }(-1)) \\
& -0,446822330054 * \text { RESID }(-1))^{\wedge} 1,12233499281+0,752897200065 \\
& \text { @SQRT }(\text { GARCH }(-1))^{\wedge} 1,12233499281
\end{aligned}
$$

PGARCH $=0,00059+(0,752897 * 0,384973)+(0,212013 * 0,495181)$

$$
=0,395419653
$$

Volatilite $=\sqrt{0,395419653}=\% 62,88$ 
Dolar serisi için uygun TARCH model oluşturularak Tablo 8'de model çıtısı verilmiştir.

Tablo 8: Dolar Serisi TARCH Model Çıktısı

\begin{tabular}{lllll}
\hline Variable & Coefficient & Std. Error & Z-Statistic & Prob. \\
\hline $\mathrm{C}$ & 0.000498 & 0.000126 & 3.958755 & 0.0001 \\
$\mathrm{AR}(3)$ & -0.017082 & 0.020279 & -0.842364 & 0.3996 \\
$\mathrm{MA}(1)$ & 0.023646 & 0.020327 & 1.163303 & 0.2447 \\
\hline $\mathrm{C}$ & $2.24 \mathrm{E}-06$ & $2.84 \mathrm{E}-07$ & 7.885789 & 0.0000 \\
$\mathrm{RESID}(-1)^{\wedge} 2$ & 0.182161 & 0.010978 & 16.59390 & 0.0000 \\
RESID(-1)^2*(RESID(-1)<0) & -0.080543 & 0.011471 & -7.021349 & 0.0000 \\
GARCH(-1) & 0.831316 & 0.009811 & 84.73263 & 0.0000 \\
\hline R-squared & 0.006416 & Mean dependent var & 0.000650 \\
Adjusted R-squared & 0.005724 & S.D. dependent var & 0.008763 \\
S.E. of regression & 0.008738 & Akaike info criterion & -7.013805 \\
Sum squared resid & 0.219036 & Schwarz criterion & -6.999272 \\
Log likelihood & 10078.82 & Hannan-Quinn criter. & -7.008566 \\
Durbin-Watson stat & 1.862029 & & & \\
\hline
\end{tabular}

$$
\begin{gathered}
\text { GARCH }=2,24315846099 e-06+0,182160633726 \\
\text { RESID }(-1)^{\wedge} 2-0,0805431818508 * \text { RESID }(-1)^{\wedge} 2 *(\text { RESID }(-1) \\
<0)+0,831316015866 * \text { GARCH }(-1) \\
\text { GARCH }=2,24 E-06+(0,182161 * 0,000108)+(-0,080543 * 0,000000) \\
+(0,831316 * 0,368416)=0,306292 \\
\text { Volatilite }=\sqrt{(0,306292)=\% 55,34}
\end{gathered}
$$

TARCH modelleme sonrasında ARCH etkisinin olup olmadığının belirlenebilmesi için ARCH testi yapılarak Tablo 9'da gösterilmiştir.

Tablo 9: TARCH Modelleme Sonrası Altın, Bist 100 ve Dolar Serileri ARCH Testi

\begin{tabular}{llll}
\hline & Altın & Bist 100 & Dolar \\
\hline F-statistic & 0.516348 & 0.007740 & 9.769014 \\
Prob, F & $(0.4725)$ & $(0.9299)$ & $(0.0018)$ \\
Obs*R-squared & 0.516615 & 0.007745 & 9.742650 \\
Prob, Chi-Square & $(0.4723)$ & $(0.9299)$ & $(0.0018)$ \\
\hline
\end{tabular}

Tablo 9'da bütün modellerde ARCH etkisi olduğu görülmektedir. Bu durumda TARCH modeller kullanılabilir. TARCH modeli ile elde edilen altın koşullu varyans serisi dağılımları Grafik 3'te gösterilmiştir. 
Grafik 3. TARCH Modelle Elde Edilen Altın Koşullu Varyans Serisi Dağılımları.
0,006000
0,004000
0,002000
Altın getiri serisi
0,000000

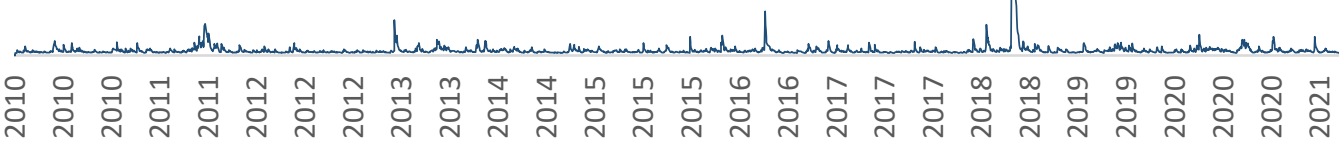

Grafik 3'te görüleceği üzere altın ve Dolar serisi 14/08/2018 tarihinde standart volatilite düzeylerinin üzerinde bir volatilite göstermiştir. PARCH modeli ile elde edilen Bist 100 koşullu varyans serisi dağılımları Grafik 4'de gösterilmiştir.

Grafik 4: PARCH Modelle Elde Edilen Bist 100 Koşullu Varyans Serisi Dağılımları.

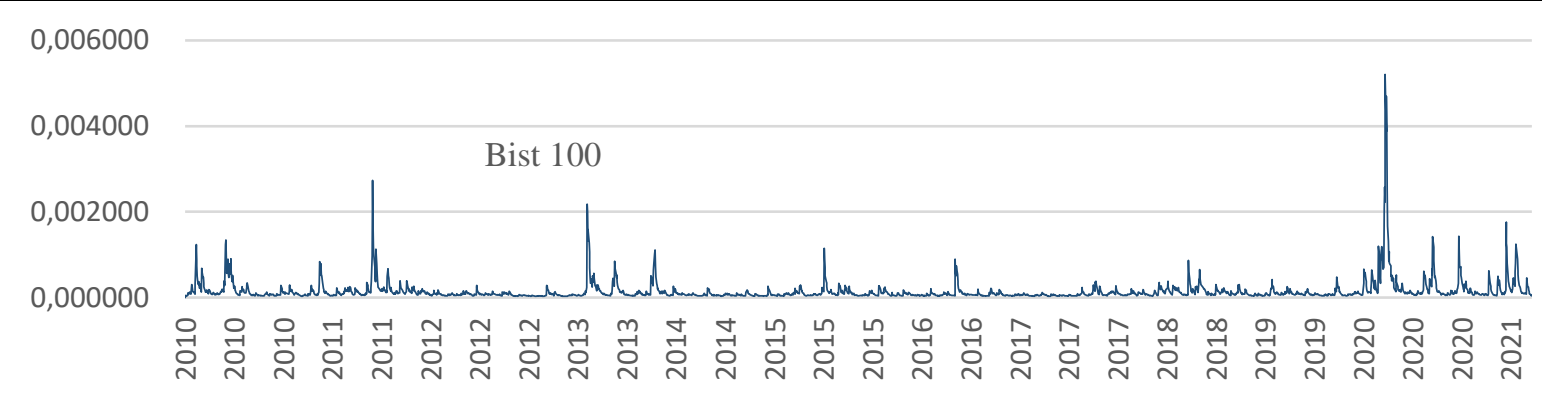

Grafik 4'de görüleceği üzere Bist 100 serisi ise, 04-07/2013 döneminde standart volatilite düzeylerinin üzerinde bir volatilite göstermiştir. TARCH modeli ile elde edilen Dolar koşullu varyans serisi dağılımları Grafik 5'te gösterilmiştir.

Grafik 5: TARCH Modelle Elde Edilen Dolar Koşullu Varyans Serisi Dağılımları.

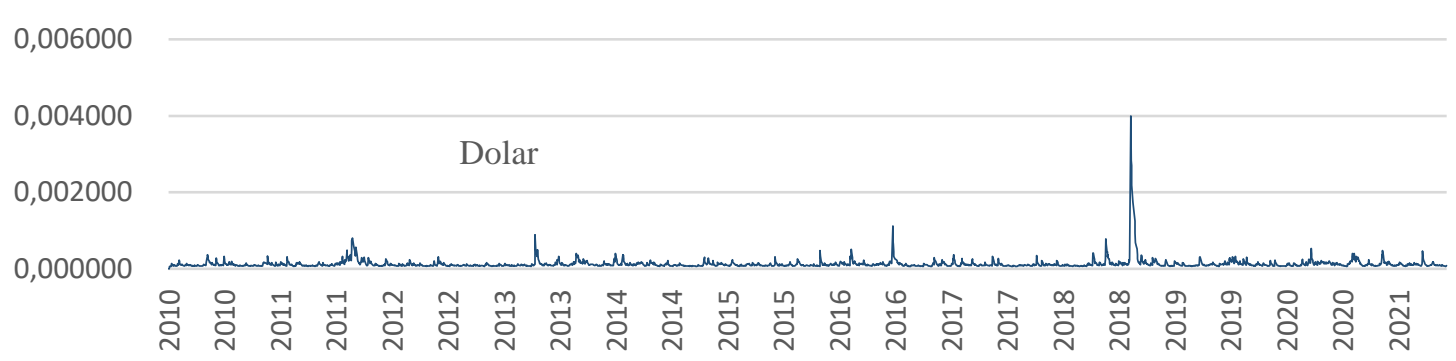

Grafik 5'te görüleceği üzere Dolar serisi 14/08/2018 tarihinde standart volatilite düzeylerinin üzerinde bir volatilite göstermiştir.

Altın, Dolar serileri için TARCH model ile bulunan ve Bist 100 serisi için PARCH model ile bulunan volatilite değerleri kullanılarak her bir seri için ayrı ayrı RMD ve portföy RMD değerleri hesaplanabilir.

Altın serisi \%95 ve \%99 oranlarına göre 1, 10 gün ve 1 yıl (252) için yüzde olarak ayrı ayrı RMD değerleri şu şekilde hesaplanabilir. 
$\mathrm{Z}=0,95$ güven düzeyi ve $\mathrm{T}=1$ gün için;

$\mathrm{RMD}=\mathrm{Z}_{0,95} * \sigma * \sqrt{1}=1,65 * 0,011450 * 1=0,019 \Rightarrow \% 1,9$

$\mathrm{Z}=0,95$ güven düzeyi ve $\mathrm{T}=10$ gün için;

$\mathrm{RMD}=\mathrm{Z}_{0,95} * \sigma * \sqrt{10}=1,65 * 0,011450 * 3,16=0,060 \Rightarrow \% 6$

$\mathrm{Z}=0,95$ güven düzeyi ve $\mathrm{T}=252$ gün için;

$\mathrm{RMD}=\mathrm{Z}_{0,95} * \sigma * \sqrt{252}=1,65 * 0,011450 * 15,87=0,300 \Rightarrow \% 30$

$\mathrm{Z}=0,99$ güven düzeyi ve $\mathrm{T}=1$ gün için;

$\mathrm{RMD}=\mathrm{Z}_{0,99} * \sigma * \sqrt{1}=2,33 * 0,011450 * 1=0,027 \Rightarrow \% 2,7$

$\mathrm{Z}=0,99$ güven düzeyi ve $\mathrm{T}=10$ gün için;

$\mathrm{RMD}=\mathrm{Z}_{0,99} * \sigma * \sqrt{10}=2,33 * 0,011450 * 3,16=0,084 \Rightarrow \% 0,4$

$\mathrm{Z}=0,99$ güven düzeyi ve $\mathrm{T}=252$ gün için;

$\mathrm{RMD}=\mathrm{Z}_{0,99} * \sigma * \sqrt{252}=2,33 * 0,011450 * 15,87=0,424 \Rightarrow \% 42,4$

Bist 100 serisi $\% 95$ ve $\% 99$ oranlarına göre 1,10 gün ve 1 yıl (252) için yüzde olarak ayrı ayrı RMD değerleri şu şekilde hesaplanabilir,

$\mathrm{Z}=0,95$ güven düzeyi ve $\mathrm{T}=1$ gün için;

$\mathrm{RMD}=\mathrm{Z}_{0,95} * \sigma * \sqrt{1}=1,65 * 0,025335 * 1=0,042 \Rightarrow \% 4,2$

$\mathrm{Z}=0,95$ güven düzeyi ve $\mathrm{T}=10$ gün için;

$\mathrm{RMD}=\mathrm{Z}_{0,95} * \sigma * \sqrt{10}=1,65 * 0,025335 * 3,16=0,132 \Rightarrow \% 13,2$

$\mathrm{Z}=0,95$ güven düzeyi ve $\mathrm{T}=252$ gün için;

$\mathrm{RMD}=\mathrm{Z}_{0,95} * \sigma * \sqrt{252}=1,65 * 0,025335 * 15,87=0,664 \Rightarrow \% 66,4$

$\mathrm{Z}=0,99$ güven düzeyi ve $\mathrm{T}=1$ gün için;

$\mathrm{RMD}=\mathrm{Z}_{0,99} * \sigma * \sqrt{1}=2,33 * 0,013158 * 1=0,059 \Rightarrow \% 5,9$

$\mathrm{Z}=0,99$ güven düzeyi ve $\mathrm{T}=10$ gün için;

$\mathrm{RMD}=\mathrm{Z}_{0,99} * \sigma * \sqrt{10}=2,33 * 0,025335 * 3,16=0,187 \Rightarrow \% 18,7$

$\mathrm{Z}=0,99$ güven düzeyi ve $\mathrm{T}=252$ gün için;

$\mathrm{RMD}=\mathrm{Z}_{0,99} * \sigma * \sqrt{252}=2,33 * 0,025335 * 15,87=0,937 \Rightarrow \% 93,7$

Dolar serisi \%95 ve \%99 oranlarına göre 1, 10 gün ve 1 yıl (252) için yüzde olarak ayrı ayrı RMD değerleri şu şekilde hesaplanabilir,

$\mathrm{Z}=0,95$ güven düzeyi ve $\mathrm{T}=1$ gün için;

$\mathrm{RMD}=\mathrm{Z}_{0,95} * \sigma * \sqrt{1}=1,65 * 0,010431 * 1=0,017 \Rightarrow \% 17$ 
$\mathrm{Z}=0,95$ güven düzeyi ve $\mathrm{T}=10$ gün için;

$$
\mathrm{RMD}=\mathrm{Z}_{0,95} * \sigma * \sqrt{10}=1,65 * 0,010431 * 3,16=0,054 \Rightarrow \% 5,4
$$

$\mathrm{Z}=0,95$ güven düzeyi ve $\mathrm{T}=252$ gün için;

$$
\mathrm{RMD}=\mathrm{Z}_{0,95} * \sigma * \sqrt{252}=1,65 * 0,010431 * 15,87=0,273 \Rightarrow \% 27,3
$$

$\mathrm{Z}=0,99$ güven düzeyi ve $\mathrm{T}=1$ gün için;

$$
\mathrm{RMD}=\mathrm{Z}_{0,99} * \sigma * \sqrt{1}=2,33 * 0,010431 * 1=0,024 \Rightarrow \% 2,4
$$

$\mathrm{Z}=0,99$ güven düzeyi ve $\mathrm{T}=10$ gün için;

$$
\mathrm{RMD}=\mathrm{Z}_{0,99} * \sigma * \sqrt{10}=2,33 * 0,010431 * 3,16=0,077 \Rightarrow \% 7,7
$$

$\mathrm{Z}=0,99$ güven düzeyi ve $\mathrm{T}=252$ gün için;

$$
\mathrm{RMD}=\mathrm{Z}_{0,99} * \sigma * \sqrt{252}=2,33 * 0,010431 * 15,87=0,386 \Rightarrow \% 38,6
$$

Altın, Bist 100 ve Dolar serilerinden oluşan portföy RMD değerleri 4 nolu formülde matrisler kullanılarak şu şekilde hesaplanabilir.

$$
\begin{aligned}
R M D_{p} & =\sqrt{\left[\begin{array}{lll}
0,00013 & 0,00064 & 0,00011
\end{array}\right]\left[\begin{array}{ccc}
1 & 0,1503 & 1 \\
0,1503 & 1 & 0,1503 \\
1 & 0,1503 & 1
\end{array}\right]\left[\begin{array}{l}
0,00013 \\
0,00064 \\
0,00011
\end{array}\right]} \\
R M D_{p} & =\sqrt{0,000000516}
\end{aligned}
$$
olacaktır.

Portföydeki serilerin ağırlıklarının eşit dağıldığı varsayımı altında portföy volatilitesi şu şekilde

$$
\begin{aligned}
& R M D_{p}=\sqrt{[0,000000516]\left[\begin{array}{lll}
\frac{1}{3} & \frac{1}{3} & \frac{1}{3}
\end{array}\right]=0,0000001719} \\
& R M D_{p}=\sqrt{[0,0000001719]\left[\begin{array}{l}
\frac{1}{3} \\
\frac{1}{3} \\
\frac{1}{3}
\end{array}\right]}= \\
& R M D_{p}=0,0000000573
\end{aligned}
$$

Volatilite $($ Standart sapma $)=0,0002=\% 0,02$

Elde edilen bu volatilite değeri üzerinden $Z=0,95$ güven düzeyi ve $T=1$ gün için $R M D$ değerleri 3 nolu formül kullanılarak hesaplanabilir.

$\mathrm{Z}=0,95$ güven düzeyi ve $\mathrm{T}=1$ gün için;

$$
\mathrm{RMD}=\mathrm{Z}_{0,95} * \sigma * \sqrt{1}=1,65 * 0.02 * 1=0.0004 \Rightarrow \% 0,04
$$

$\mathrm{Z}=0,95$ güven düzeyi ve $\mathrm{T}=10$ gün için;

$$
\mathrm{RMD}=\mathrm{Z}_{0,95} * \sigma * \sqrt{1}=1,65 * 0.02 * 3,16=0.00125 \Rightarrow \% 0,13
$$


$\mathrm{Z}=0,95$ güven düzeyi ve $\mathrm{T}=252$ gün için;

$$
\mathrm{RMD}=\mathrm{Z}_{0,95} * \sigma * \sqrt{1}=1,65 * 0.02 * 15,87=0.00627 \Rightarrow \% 0,63
$$

$\mathrm{Z}=0,99$ güven düzeyi ve $\mathrm{T}=1$ gün için;

$$
\mathrm{RMD}=\mathrm{Z}_{0,95} * \sigma * \sqrt{1}=2.33 * 0.02 * 1=0.00056 \Rightarrow \% 0,06
$$

$\mathrm{Z}=0,99$ güven düzeyi ve $\mathrm{T}=10$ gün için;

$$
\mathrm{RMD}=\mathrm{Z}_{0,95} * \sigma * \sqrt{1}=2.33 * 0.02 * 3,16=0.00176 \Rightarrow \% 0,18
$$

$\mathrm{Z}=0,99$ güven düzeyi ve $\mathrm{T}=252$ gün için;

$$
\mathrm{RMD}=\mathrm{Z}_{0,95} * \sigma * \sqrt{1}=2.33 * 0.02 * 15,87=0.00885 \Rightarrow \% 0,89
$$

Tek tek hesaplanan varlıkların RMD değerler toplamları ile portföy RMDp değeri karşılaştırması tablo 9'da verilmiştir.

Tablo 10: RMD karşılaştırma tablosu

\begin{tabular}{llcc}
\hline & RMD değerleri toplamı & Portföy RMDp değeri \\
\hline $\mathrm{Z}=0,95$ & güven düzeyi ve $\mathrm{T}=1$ gün için; & 0,0779 & 0,00040 \\
$\mathrm{Z}=0,95$ & güven düzeyi ve $\mathrm{T}=10$ gün için; & 0,2464 & 0,00125 \\
$\mathrm{Z}=0,95$ & güven düzeyi ve $\mathrm{T}=252$ gün için; & 1,2367 & 0,00627 \\
$\mathrm{Z}=0,99$ & güven düzeyi ve $\mathrm{T}=1$ gün için; & 0,1100 & 0,00056 \\
$\mathrm{Z}=0,99$ & güven düzeyi ve $\mathrm{T}=10$ gün için; & 0,3479 & 0,00176 \\
$\mathrm{Z}=0,99$ & güven düzeyi ve $\mathrm{T}=252$ gün için; & 1,7464 & 0,00885 \\
\hline
\end{tabular}

Tablo 10'da görüldüğü gibi $\mathrm{Z}=0,95$ güven düzeyi ve $\mathrm{T}=1$ gün için, tek tek RMD değerleri toplamı 0,0779 iken portföyün RMDp değeri 0,00040 seviyesine düşmüştür. Bu sonuç portföy etkisinin olduğunun bir göstergesidir. Daha iyi karşılaştırma yapabilmek için \%95 ve \%99 düzeyinde 1 , 10 ve 252 günlük RMD ve $\mathrm{RMD}_{\mathrm{p}}$ değerlerinin portföy etkisi 6 nolu grafikte gösterilmiştir.

Grafik 6: RMD ve RMD ${ }_{p}$ Değerlerinin \%99 ve \%95 Güven Düzeylerinde 1, 10 ve 252 Günlük Etkisi.

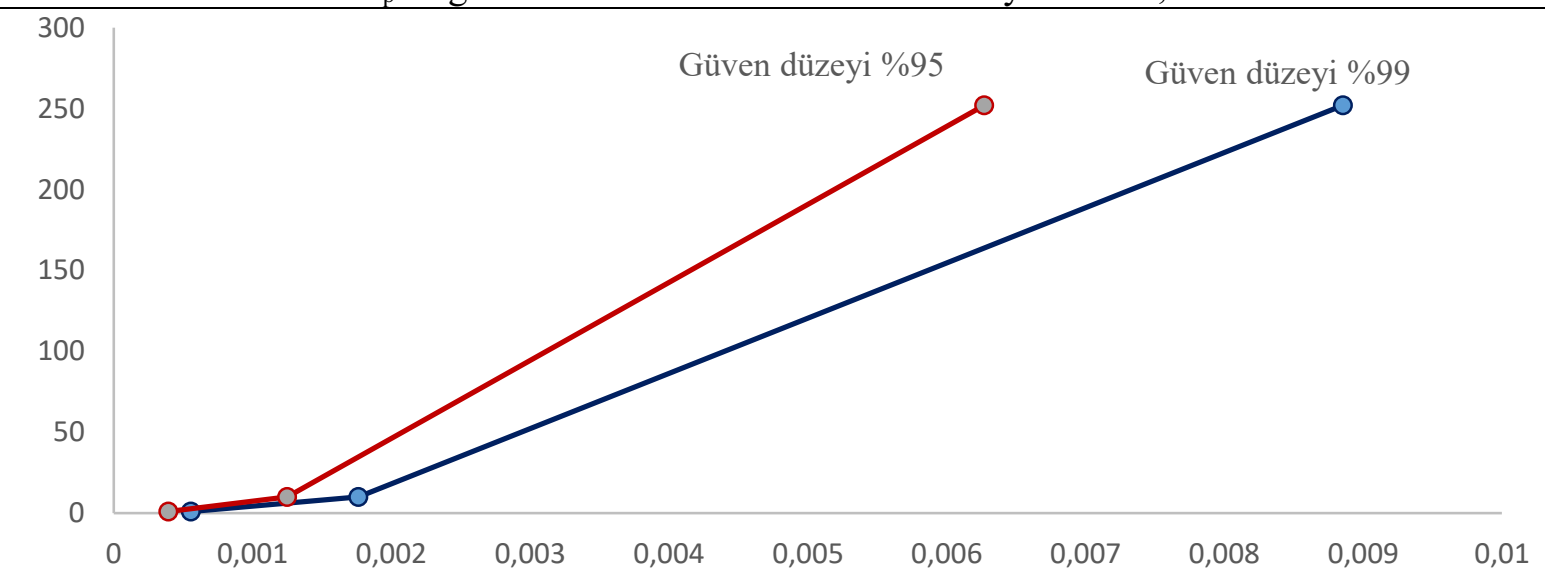


Grafikte 6'da görüldüğü gibi 1 gün bile olsa portföyün risk düzeyi daha düşüktür.

RMD düzeyi ve RMDp değerleri gün sayısı arttıkça daha fazla artmaktadır. Güven düzeyi düştükçe risk artmaktadır. Altın, Bist 100 ve Dolar serilerinden oluşan portföyün güven düzeylerine göre en fazla zarar olasıllığ Tablo 11'de sunulmuştur.

Tablo 11: Güven Düzeylerine Göre En Fazla Zarar Olasılığı

\begin{tabular}{llc}
\hline Güven Düzeyi & Gün & En Fazla Zarar Olasılı̆̆ \\
\hline $\mathbf{Z = 0 , 9 5}$ & $\mathrm{T}=1$ & $\% 0,04$ \\
$\mathbf{Z = 0 , 9 5}$ & $\mathrm{T}=10$ & $\% 0,12$ \\
$\mathbf{Z = 0 , 9 5}$ & $\mathrm{T}=252$ & $\% 0,63$ \\
$\mathbf{Z = 0 , 9 9}$ & $\mathrm{T}=1$ & $\% 0,06$ \\
$\mathbf{Z = 0 , 9 9}$ & $\mathrm{T}=10$ & $\% 0,18$ \\
$\mathbf{Z = 0 , 9 9}$ & $\mathrm{T}=252$ & $\% 0,89$ \\
\hline
\end{tabular}




\section{Sonuç, Tartışma ve Öneriler}

Finansal varlıkların zaman içerisinde volatiliteleri değişmektedir. İyi haber veya kötü haberlerin arttığı dönemlerde ise volatilite etkisinin de daha fazla arttı̆̆ 1 bilinmektedir. Finansal zaman serilerindeki etkiyi azaltmanın bir yolu da finansal varlıklardan bir portföy oluşturmaktır. Portföy etkisinin zararı nasıl azalttığını göstermek için yapılan bu çalışmada eşit ağırlığa sahip altın, Bist 100 endeksi ve Dolardan oluşan üç finansal varlık için RMD analizi yapılmıştır. RMD analizi, bir portföyün belirli bir olasılıkla en fazla ne kadar zarara uğratacağını gösterir.

Portföydeki varlıklara ait 05.01.2010-10.06.2021 tarihler arası veriler kullanılmıştır. Bist 100 endeksi ve Dolar'a ait 2875 iş günü kapanış verileri EVDS veri tabanından elde edilmiştir. Altına ait veriler ise, Borsa İstanbul veri tabanından elde edilmiştir. Hesaplamalarda Eviews12 ve Excel yazılımı kullanılmıştır. Kayıp olan birkaç değer için önceki gün ile sonraki gün ortalama değerler atanmıştır. Finansal zaman serileri trend içerdikleri için basit getiri formülü kullanılarak getiri değerleri ile analiz yapılmıştır.

İlk önce, Finansal zaman serilerinde analiz yapılabilmesi için gerekli istatistiksel analizler yapılmıştır. Bu analizler sonucunda serilerin normal dağılmaması, değişen varyansa sahip olması ve otokorelasyonlu olması nedeniyle RMD analizinin doğru sonuçlar üretmeyeceği görülmüştür. Dolayısıyla RMD analizinde koşullu varyans ARMA süreci ile modellenerek GARCH modelleriyle volatilite hesaplanmıştır.

İkinci olarak, ARMA model belirlenmiştir. Altın ve Dolar için ARMA (3,1), Bist 100 için ARMA $(1,1)$ uygun model olarak belirlenmiştir. Bu ARMA modeller için ARCH etkisinin olup olmadığ test edilmiştir. ARCH etkisi var olduğu belirlenen bu seriler için GARCH analizi yapılması uygun bulunmuştur.

Üçüncü olarak, GARCH model seçiminde kullanılan kriterlere göre GARCH, TARCH, EGARCH VE PARCH modelleri karşılaştııılmıştır. Altın ve Dolar için TARCH model seçilmiştir. Bist 100 endeksi için PARCH modelin uygun model olduğu belirlenmiştir. Kurulan TARCH ve PARCH modellere göre ARCH etkisinin giderilip giderilmediği analiz edilmiştir.

Dördüncü olarak, ARCH etkisinin kalmadığı anlaşılan bu seriler için bulunan volatilite değerleri ile RMD analizi yapılmıştır. RMD analizi, \%95 ve \%99 güven düzeylerine göre 1, 10 ve 252 gün için her bir seriye ayrı ayrı ve eşit ağırlıklı portföy oluşturularak uygulanmıştır.

Sonuç olarak, Altın, Bist 100 ve Dolar serilerinde güven düzeyi düştükçe risk artmaktadır. Gün sayısı arttıkça risk daha fazla artış göstermektedir. RMD ve RMDp değerleri gün sayısı arttıkça daha fazla artmaktadır. Altın, Bist 100 ve Dolar serisinden oluşan portföyde portföy etkisi olduğu açıkça görülmüştür. Farklı seriler, zaman aralığı veya farklı ağırlıklarda oluşturulacak portföylerle yapılacak analizler başka çalışmalar için önerilebilir. 


\section{Kaynakça}

Akbulaev, N. and Aliyeva, B. (2018). Risk Exposure Value: An Application on Derivatives. Eurasian Academy of Sciences Eurasian Econometrics, Statistics \& Emprical Economics Journal Volume:10 S: 23- 38. http://dx.doi.org/10.17740/eas.stat.2018-V10-02.

Altay, E. (2015), Bankacıllkta Risk: Piyasa Riski Kredi Riski ve Operasyonel Riskin Ölçümü ve Yönetimi. Derin Yayınları.

Altayligil, Y. (2008). Graw ve Ewma ile Riske Maruz Değer: Altın Getirisi için Bir Uygulama. Sosyal Bilimler Dergisi. (1), 33-41.

Altıntaş, A. (2006). Bankacılıkta Risk Yönetimi ve Sermaye Yeterliliği. Turhan Kitabevi.

Andersson, F., Mausser, H., Rosen, D. and Uryasev, S. (2001). Credit Risk Optimization with Conditional Value-at-Risk Criterion. Mathematical Programming. 89(2), 273-291.

Angelidis, T., Benos, A. and Degiannakis, S. (2004). The Use of GARCH Models in VaR Estimation. Statistical Methodology. 1(1-2), 105-128.

Aridi, N. A., Cheong, C. W. and Hooi, T. S. (2018). An Estimation of Value at Risk Using GARCH Models for The Conventional and Islamic Stock Market in Malaysia. International Journal of Academic Research in Business and Social Sciences. 8(11).

Atakan, T. (2009). İstanbul Menkul Kıymetler Borsasında Değişkenliğin (volatilitenin) ARCH-GARCH Yöntemleri ile Modellenmesi. Yönetim Dergisi, 62, 48-61.

Avşarlıgil, N., Demir, Y. ve Doğru, E. (2015). Riske Maruz Değer Ölçüm Yöntemleri Aracılığıyla BIST’te İşlem Gören Spor Kulüpleri Üzerine Bir Uygulama. Journal of Social Sciences Eskisehir Osmangazi University/Eskisehir Osmangazi Üniversitesi Sosyal Bilimler Dergisi. 16(1).

Baas, S., Ramamasy, S., Dey de Pryck, J. and Battista, F. (2008). Disaster risk management systems analysis: A guide book.

Babacan, C. (2017). Sigorta Şirketlerinin Mali Yatırımlarının Piyasa Risklerinin Ölçümlenme Yöntemleri Üzerine Bir Uygulama. İstanbul Ticaret Üniversitesi Sosyal Bilimler Dergisi. 16(31), 583.

Babaşova, S. (2012). Doğrusal Olmayan Zaman Serisi Verilerinin Modellenmesinde Kullanılan Değişen Varyanslılık Testlerinin Karşılaştırmalı Analizi Üzerine Bir Araştırma (Doctoral Dissertation, DEÜ Sosyal Bilimleri Enstitüsü).

Babat, O., Vera, J.C. and Zuluaga, L.F. (2018). Computing Near-Optimal Value-at-Risk Portfolios Using Integer Programming Techniques. European Journal of Operational Research. 266(1). 304315

Basel Committee on Banking Supervision. (2016). Minimum Capital Requirements for Market Risk, Basel: Bank for International Settlements.

Bayçelebi, B. E. ve Ertuğrul, M. (2020). BIST Banka Endeksi Volatilitesinin GARCH Modelleri Kullanılarak Modellenmesi. Anadolu Üniversitesi Sosyal Bilimler Dergisi, 20(1), 233-244.

Belasri, Y. and Ellaia, R. (2017). Estimation of Volatility and Correlation with Multivariate Generalized Autoregressive Conditional Heteroskedasticity Models: An Application to Moroccan Stock Markets. International Journal of Economics and Financial Issues. 7(2), 384. 
Berggren, E. and Folkelid, F. (2015). Which GARCH Model is Best For Value-at-Risk? (Tez). https://www.diva-portal.org/smash/get/diva2:788857/FULLTEXT 01.pdf. (Erişim Tarihi: 14.06.2021)

Best, P. (2000). Implementing Value at risk. John Wiley \& Sons.

Bilir, H. ve Aslan, O. (2020). Hisse Senetlerinden Oluşturulan Portföyün Riske Maruz Değerinin Hesaplanmas1. Ankara Üniversitesi SBF Dergisi. 75(3). 1171-1201. Doi:10.33630/ausbf.598833.

Bitaraf, S. and Shahriari, M. (2012). Risk Assessment and Decision Support. In Internationa Symposium on Occupational Safety and Hygiene, 9th-10th February 2012, pp 65-69 (pp. 65-71).

Boğa, S. (2020). Finansal Açıklığın Gelir Eşitsizliği Üzerine Etkisi: Türkiye İçin Bir Zaman Serisi Analizi. Stratejik ve Sosyal Araştırmalar Dergisi. 4(1). 41-56. Doi:10.30692/sisad.689946.

Bollerslev, T. (1986). Generalized Autoregressive Conditional Heteroskedasticity. Journal of Econometrics. 31(3). 307-327.

Butler, C. (1999). Mastering Value at Risk, A Step-By-Step Guide to Understanding and Applying VaR. Financial Times Pitman Publishing. Market Editions, London.

Campbell, J.Y., Lo, A.W. and MacKinlay, A. C. (1998). The Econometrics of Financial Markets: Princeton University Press. 1997. Econometric Theory. 14(5), 610. doi:10.1017/S0266466698145073.

Cangürel, O., Dizdar, S., Karakoç, A., Mimaroğlu, B. Y., Teker, B. Y. ve Kaycı, İ. (2012). Sorularla Basel 2,5. Bankacılık Düzenleme ve Denetleme Kurumu. Ankara.

Cera, G., Cera, E. and Lito, G. (2013). A Garch Model Approach to Calculate the Value at Risk of Albanian Lek Exchange Rate. European Scientific Journal. 9(25).

Cihangir, Ç. K. ve Uğurlu, E. (2017). Altın Piyasasında Asimetrik Oynaklık: Türkiye için Model Önerisi. İşletme Araştırmaları Dergisi. 9/3 (2017) 284-299. Doi: 10.20491/isarder.2017.300.

Çabuk, A., Özmen H. ve Kökcen, M. A. (2011). Koşullu Varyans Modelleri: İMKB Serileri Üzerine Bir Uygulama. Çukurova Üniversitesi İktisadi ve İdari Bilimler Fakültesi Dergisi. 15(2). S 1-18.

Çekici, E. M. (2017). Parametrik RMD (VaR) İncelemesi: BIST’te İşlem Gören Sigorta Şirketleri Üzerine Bir araştırma. Marmara Üniversitesi Öneri Dergisi. Cilt 12, Say1 48, ISSN 1300-0845. Ss. 217-225. Doi: 10.14783/maruoneri.vi.331669.

Çil Yavuz, N. (2015). Finansal Ekonometri. İkinci Basım. Der Yayınları. İstanbul.

Ding, Z., Granger, C. W. and Engle, R. F. (1993). A Long Memory Property of Stock Market Returns and a New Model. Journal of Empirical Finance, 1(1), 83-106.

Dovd, K. (1999). Beyond Value at Risk: The New Science of Risk Management. John Wiley Sons Ltd., England.

Echaust, K. (2019). Financial Risk Measurement:Financial Engineering. Wydawnictwo Uniwersytetu Ekonomicznego W. Poznaniu. pp. 35-62.

Elçi, Ö. and Noyan, N, (2018). A Chance-Constrained Two-Stage Stochastic Programming Model for Humanitarian Relief Network Design. Transportation Research Part B: Methodological. 108, 5583.

Engle R. F. (2002). Dynamic Conditional Correlation. Journal of Business \& Economic Statistics. 20:3, 339-350. Doi:10.1198/073500102288618487. 
Engle, R. F. (1982). Autoregressive Conditional Heteroscedasticity with Estimates of The Variance of United Kingdom Inflation. Econometrica: Journal of the Econometric Society, 987-1007.

Fernandez, V. (2009). Value at Risk under Heterogeneous Investment Horizons and Spatial Relations. Advance Praise for The VaR Implementation Handbook. 463.

Ghasemi, A. and Zahediasl, S. (2012). Normality Tests for Statistical Analysis: A Guide For NonStatisticians. Int J Endocrinol Metab. 2012;10(2):486-489. Doi:10,5812/ijem,3505.

Gujarati, D. (2015). Econometrics by Example (2nd ed.). London, United Kingdom: Macmillan International Higher Education.

Gujarati, D. (2016). Örneklerle Ekonometri. N. Bolatoğlu. Çev.). Ankara: BB101 Yayınları.

Güriş, S., Çağlayan, E. ve Güriş, B. (2013). EViews ile Temel Ekonometri (2. basım). İstanbul: DER Yayınları.

Hung, K., Yang, C.W., Zhao, Y.F. and Lee, K.H. (2018). Risk Return Relationship in the Portfolio Selection Models. Theoretical Economics Letters. 8, 358-366.

Iş1klar, Z. E. (2016). İMKB Ulusal 100 Endeksi Getiri Volatilitesinin Analizi Üzerine Bir Araştırma. Selçuk Üniversitesi Sosyal ve Teknik Araştırmalar Dergisi. (12), 245-260.

Jorion, P. (2007). Value at Risk: The New Benchmark for Managing Financial Risk. The McGraw-Hill Companies, Inc. New York.

Karagöz, Y. (2016). SPSS 23 ve AMOS 23 Uygulamalı İstatistiksel Analizler. Nobel Akademik Yayıncilik.

Kellner, R. and Rösch, D. (2016). Quantifying Market Risk With Value-at-Risk or Expected Shortfall? - Consequences for Capital Requirements and Model Risk. Journal of Economic Dynamics and Control. Volume 68. Pages 45-63. ISSN 0165-1889. https://doi.org/10.1016/j.jedc.2016.05.002.

Kendirli, S. ve Karadeniz, G. (2012). 2008 Kriz Sonras1 İMKB 30 Endeksi Volatilitesinin Genelleştirilmiş Arch Modeli ile Tahmini. Kahramanmaraş Sütçü İmam Üniversitesi İktisadi ve İdari Bilimler Fakültesi Dergisi. 2(2). 95-104.

Koima, J. K., Mwita P. N. and Nassiuma. D. K. (2015). Volatility Estimation of Stock Prices Using Garch Method. European Journal of Business and Management. ISSN 2222-1905 (Paper) ISSN 2222-2839 (Online) Vol.7. No.19. 2015.

Krokhmal, P., Palmquist, J. and Uryasev, S. (2002). Portfolio Optimization with Conditional Value-atRisk Objective and Constraints. Journal of Risk, 4. 43-68.

Kutlar, A. ve Torun, P. (2013). İMKB 100 Endeksi Günlük Getirileri için Uygun Genelleştirilmiş Farklı Varyans Modelinin Seçimi. Erciyes Üniversitesi İktisadi ve İdari Bilimler Fakültesi Dergisi. (42). $1-24$.

Lebo, M. and Box-Steffensmeier, J. (2008). Dynamic Conditional Correlations in Political Science. American Journal of Political Science, 52(3), 688-704.

Longerstaey, J. and Spencer, M. (1996). Riskmetricstm-Technical Document. Morgan Guaranty Trust Company of New York: New York.

Moran, J.L. and Solomon, P.J. (2017). Volatility in HighFrequency Intensive Care Mortality Time Series: Application of Univariate and Multivariate GARCH Models. Open Journal of Applied Sciences. 7. 385-411.

Munniksma, K. (2006). Credit Risk Measurement Under Basel II. BMI Paper. Vrije Universiteit. 
Nelson, D. B. (1991). Conditional Heteroskedasticity in Asset Returns: A New Approach. Econometrica: Journal of the Econometric Society, 347-370.

Poon, S. (2005). A Practical Guide to Forecasting. John Wiley \& Sons Ltd,. England. ISBN-13 978-0470-85613-0 (HB).

Rockafellar, R.T. and Uryasev, S. (2000), Optimization of Conditional Value-at-Risk. Journal of Risk. 2. 21-42.

Sarıkovanlık, V., Koy, A., Akkaya, M., Yıldırım, H. H. ve Kantar, L. (2019). Finans Biliminde Ekonometri Uygulamaları. Ankara: Seçkin Yayıncılık.

Sevüktekin, M. ve Nargeleçekenler, M. (2006). İstanbul Menkul Kıymetler Borsasında Getiri Volatilitesinin Modellenmesi ve Ön raporlanmas1. Ankara Üniversitesi SBF Dergisi. 61(4). 243265.

Šotić, A. and Rajić, R. (2015). The review of the definition of risk. Online Journal of Applied Knowledge Management, 3(3), 17-26.

Şencan, İ. (2017). BIST Altın Endeksi Oynaklığı Analizi ve Performans Ölçümü. Maliye Finans Yazılart. 31(107).

Terzioğlu, M. K. (2018). Riske Maruz Değer Kavram ve Uygulamalar. Ankara. Gazi Kitabevi.

Toma, S. V., Chiriţă, M. and Şarpe, D. (2012). Risk and uncertainty. Procedia Economics and Finance, 3, 975-980. doi: 10.1016/S2212-5671(12)00260-2

Treasury, H. M. (2004). The orange book: Management of risk-principles and concepts. London: HM Treasury.

Türker, H. (2009). Riske Maruz Değer (Value at Risk) ve Stres Testi: Global Finansal Kriz Sonrası Etkinliklerinin Değerlendirilmesi. Ankara: SPK Araştırma Raporu.

Uğur, A. ve Bingöl, N. (2017). BIST İmalat Sanayinde Riskin Ölçülmesi: Riske Maruz Değer Yöntemiyle Bir Uygulama. Ömer Halisdemir Üniversitesi İktisadi ve İdari Bilimler Fakültesi Dergisi. Y11: Ekim 2017 Cilt-Say1: 10(4) ss: 271-284. ISSN: 2564-6931. Doi:10.25287/ohuiibf.339941.

Wipplinger, E. (2007). Philippe Jorion: Value at Risk-The New Benchmark for Managing Financial Risk. Financial Markets and Portfolio Management. 21(3). 397.

Yıldırtan, D.Ç (2011) E-Views Uygulamalı Temel Ekonometri Makro Ekonomik Verilerle. Gözden Geçirilmiş 3. Bask1.

Zakoian, J. M. (1994). Threshold Heteroskedastic Models. Journal of Economic Dynamics and Control, 18(5), 931-955.

\section{İnternet Kaynakçası}

Borsa İstanbul: https://www.borsaistanbul.com/tr/sayfa/484/veri-sorgulama (Erişim Tarihi: 10.06.2021)

Merkez Bankası Veri Tabanı. Türkiye Cumhuriyet Merkez Bankası Elektronik Veri Dağıtım Sistemi (EVDS) internet sitesi: https://evds2,tcmb,gov,tr/index,php?/evds/serieMarket/collapse_1/5854/DataGroup/turkish/bie_m kbrgn/ (Erişism Tarihi: 10/06/2021) 